\title{
Hacia la paz eterna en la tierra de la sociedad posheroica: de la anarquía de la soberanía del siglo XIX al ius contra bellum de las Naciones Unidas*
}

\author{
Bernd Marquardt" Ph.D \\ Recibido: 12 de Septiembre de 2013 - Revisado: 27 de septiembre de 2013 • \\ Aprobado: 30 de septiembre de 2013
}

\section{Resumen}

El siguiente artículo pretende analizar la historia del derecho internacional público en cuanto a la transformación de la anarquía de la soberanía del siglo XIX al ius contra bellum de las Naciones Unidas, según el interés investigativo de explicar interdisciplinariamente un proceso de pacificación fundamental. En la primera parte, se caracterizará la gran violentización de las relaciones internacionales en la era de la anarquía de la soberanía (1772-1945), teniendo en cuenta el mito de un supuesto sistema de Westfalia, la creación del sistema de San Petersburgo (1772) y Viena (1815), el panorama empírico de los cambios territoriales violentos y la

\footnotetext{
* El presente texto es el resultado principal del proyecto de investigación De la anarquía de la soberanía del siglo XIX al ius contra bellum de las Naciones Unidas de la línea de investigación número 11 Constitucionalismo, relaciones internacionales y globalización del grupo de investigación CCConstitucionalismo Comparado, dirigido por el autor. Es inscrito bajo el código CC-MQ-31 en el instituto UNIJUS de la Facultad de Derecho, Ciencias Políticas y Sociales de la Universidad Nacional de Colombia y en el respectivo Gruplac de Colciencias.

** Profesor asociado en la Facultad de Derecho, Ciencias Políticas y Sociales de la Universidad Nacional de Colombia, sede Bogotá. Director del Grupo de Investigación CC - Constitucionalismo Comparado. Doctorado summa cum laude (1999) en Derecho y segundo (pos) Doctorado Superior (la Habilitation centroeuropea, 2003) de la Universidad de Sankt Gallen en Suiza. Magister (Staatsexamen) y abogado de la Universidad de Göttingen en la República Federal Alemana. Ha enseñado, entre otros, en los programas de doctorado y maestría de las Universidades de Sankt Gallen en Suiza y Linz en Austria. Experto en Derecho constitucional, Historia y teoría constitucional, Teoría del Estado, Derecho internacional público, Historia del Derecho, Derecho comparado, Derecho ambiental. Autor de 132 publicaciones, con 16 libros completos. Correo electrónico: b.marquardt@gmx.ch
} 
segunda cara de la anarquía de la soberanía en forma de los genocidios del Estado nación, para formular subsiguientemente el acercamiento a una explicación, sin olvidar tematizar el fenómeno de la creciente mundialización del llamado Derecho de los Estados civilizados y la notable excepción zonal en forma de la paz interamericana. La segunda parte se dedicará a la gran pacificación global hacia el Estado posbélico en la comunidad de la paz mundial. Se discutirá el ius contra bellum de la Organización de las Naciones Unidas (ONU) según la prohibición general del uso de la fuerza (1945) y se presentará el resultado llamativo del final de las guerras de conquista (1967). Además, se analizará el desarrollo de la justicia de la paz mundial. La contextualización se enfocará en la creación de una nueva mentalidad posheroica. Igualmente, se tendrá en cuenta la des-imperialización y las contra-tendencias actuales por el neo-belicismo preventivo y humanitario. Finalmente, se discutirá la cuestión de una Paz de los Estados comerciales para terminar con una síntesis integral de lo expuesto.

Palabras clave: derecho internacional público, transformaciones, sistema de Westfalia, anarquía de la soberanía, ius contra bellum, mentalidad posheroica

\title{
TOWARDS THE ETERNAL PEACE IN THE LAND OF THE POSTHEROIC Society: From the Anarchy of Sovereignty of The i9Th Century to the Ius Contra Bellum of THE United Nations
}

\begin{abstract}
The following article analyzes the history of public international law regarding the transformation of sovereignty anarchy of the nineteenth century into the jus contra bellum of the United Nations, according to the research interest of interdisciplinary explain fundamental process of pacification. In the first part, the great violentización of international relations in the era of anarchy of sovereignty (1772-1945) will be characterized considering the myth of an alleged Westphalian system, the creation of the system of St. Petersburg (1772) and Vienna (1815), the empirical scenario of violent territorial changes and the second face of the anarchy of sovereignty as the genocide of the nation state, subsequently to formulate the approach to an explanation, not to mention the phenomenon of theming increasing globalization of law called civilized nations and the notable exception as zonal inter-American peace. The second part is devoted to the great global peacekeeping to post- war status of
\end{abstract}


world peace community. The ius contra bellum UN will be discussed according to the general prohibition of the use of force (1945) and present the striking result of the end of the wars of conquest (1967). In addition, the development of world peace justice will be discussed. Contextualization will focus on the creation of a new post- heroic mentality. Likewise, take into account the de- imperialization and counter - current trends by the warmongering neo- preventive and humanitarian. Finally, the issue of the commercial States Peace be discussed, ending with a comprehensive synthesis of the above .

Keywords: Public international law, transformations, Westphalian system, anarchy of sovereignty, jus contra bellum, post-heroic mentality

\section{Percebendo a eterna paz na terra da sociedade Pós- heróico: Da aNARQUia da SObERANia do SÉculo i 9 PARA o IUS CONTRA bellum das Nações Unidas}

\section{Resumo}

O seguinte artigo analisa a história do direito internacional público sobre a transformação da soberania anarquia do século XIX, o jus bellum contra das Nações Unidas, de acordo com o interesse dos interdisciplinar explicar processo fundamental de pacificação pesquisa. Na primeira parte, o grande violentización das relações internacionais na era da anarquia da soberania (1772-1945) será caracterizado considerando o mito de um suposto sistema de Westfália , a criação do sistema de São Petersburgo (1772) e Viena (1815) , o cenário empírica das mudanças territoriais violentos ea segunda face da anarquia da soberania como o genocídio do Estado-nação , posteriormente, para formular a abordagem a uma explicação, para não mencionar o fenômeno da tematização crescente globalização da lei chamada nações civilizadas e a notável exceção como zonal paz inter- americano. A segunda parte é dedicada ao grande manutenção da paz global para o estado pós-guerra da comunidade paz mundial. $\mathrm{O}$ ius bellum contra ONU será discutida de acordo com a proibição geral do uso da força (1945) e apresentar o resultado surpreendente do fim das guerras de conquista (1967). Além disso, será discutido o desenvolvimento da justiça da paz mundial. Contextualização incidirá sobre a criação de uma nova mentalidade pós- heróico. Da mesma forma, levar em conta as de-imperialization e contra-corrente tendências pelo belicista neo- preventiva e humanitária. Finalmente, ser discutida a questão dos Estados Paz comercial, terminando com uma síntese abrangente das opções acima. 
Palavras-chave: Direito internacional público, transformações, sistema de Westfália, anarquia da soberania, jus bellum contra, a mentalidade pós-heróica

\section{Introducción}

El presente artículo retoma en su título la denominación de una norma de 1495: la Paz Eterna en la tierra del Sacro Imperio Romano Germánico (Marquardt, 2013, pp.47-67). Aunque el mismo intentó pacificar nada más que el espacio interno de la monarquía primaria de la Cristiandad europea de entonces, la denominación y las estrategias jurídicas y consensuales parecen una profecía del régimen de paz de las Naciones Unidas. Sin embargo, la misma no tiene la mejor reputación: si se pregunta a estudiantes en América Latina o en Europa, las respuestas indican típicamente defectos, vacios, guerras continuadas, y en general, una eficacia débil. Este artículo pretende enfocarse en otra perspectiva: si se contrasta la pacificación fundamental a partir de 1945 con la violentización excesiva entre 1772 y 1945, pueden reconocerse enormes avances. Aunque el resultado no es perfecto, se acepta, en una perspectiva universal a largo plazo, un motivo aún más profundo: la superación sistémica del belicismo de las civilizaciones agrarias y su reemplazo por la nueva lógica primaria de la sociedad posheroica.

En términos metodológicos, el estudio se basa, primordialmente, en la escuela socio-cultural y transnacional de la historia del derecho (Marquardt, 2012, pp. 16-17; Stolleis, 2009), con un enfoque temático en la historia del derecho internacional público (Grewe, 2000; Ziegler, 2007), analizando fuentes primarias en el contexto transdisciplinario de sus precondiciones y consecuencias políticas, sociales y culturales. En particular, hay que contextualizar los desarrollos jurídicos y políticos en el espejo de la teoría de la gran transformación desde la sociedad preindustrial y preilustrada a su sistema sucesor (Sieferle, 2009, pp. 1-92). De igual forma, juegan un papel significativo los estudios antropológicos y psicosociales de la violontología y la pazología (Comins Mingol, 2009, pp. 20 y ss.; Fry, 2006; Pinker, 2011; Sánchez, 2006). En ello, el lector colombiano va a ser familiarizado con una bibliografía de origen alemán y anglófono que, a pesar de un buen nivel de traducción, no es tan conocida en la zona andina. 


\section{Parte primera: la gran violentización en la era de la anarquía de la soberanía en las relaciones internacionales (1772-1945)}

\section{E1 mito de Westfalia}

Estructurando la historia del derecho internacional público, no hay duda en entender el largo siglo XIX con su prolongación hasta 1945, como una época con varias características claves comunes, por el contrario, sí hay un debate sobre su inicio. El problema radica en el mito del sistema de Westfalia, extendido en la teoría americana de las relaciones internacionales, que afirma que la Paz de Westfalia de 1648 habría sido el inicio de la modernidad del derecho internacional público, introduciendo, supuestamente, conceptos como la soberanía externa, el balance de poderes, la igualdad entre los Estados y el laicismo (D’Anieri, 2012, pp. 28 y ss.; Rojas, 2005, p. 155; Vergara Molana, 2002, p. 47).

Esta perspectiva ha sido criticada fuertemente por varios historiadores del derecho (Lesaffer, 2004, p. 9; Marquardt, 2007, pp. 103-143; Marquardt, 2009 a, pp. 44 y ss.; Osiander, 2001, pp. 251-287) e historiadores de la modernidad temprana (Duchhardt, 1999, pp. 125 y ss.; Duchhardt, 2004, pp. 45-58), pues la misma se ha alejado sustancialmente de los contenidos y los contextos de las respectivas fuentes primarias: primero, los tratados de Münster y Osnabrück no mostraron el perfil de documentos internacionales puros, sino que se manejaron como mezclas caprichosas entre elementos de tratados del derecho público europeo, pactados entre el Sacro Imperio Romano, Francia y Suecia, y varios componentes notables de leyes fundamentales que pacificaron la guerra constitucional y religiosa interna del Sacro Imperio Romano; segundo, no se puede confirmar el inicio de un nuevo régimen internacional sino se detecta una paz típica de la larga línea de documentos semejantes de 1529 a 1763; tercero, la terminología jurídica y los institutos de la Paz de Westfalia no evidencian grandes cercanías a las relaciones internacionales de la posterior era industrial, sino que fueron fuertemente ancladas en la Europa preilustrada, pues los conceptos modernos, asociados de vez en cuando a dicha paz: soberanía externa, balance de poderes, igualdad entre Estados, no injerencia en asuntos internos y secularidad, no jugaron ningún rol significativo en el texto, al menos no como principios claves de las relaciones entre los Estados de la Cristiandad 
europea de entonces. Visto así, los acuerdos de Westfalia no marcaron el inicio de una nueva época iusinternacionalista que se extendiera supuestamente hasta la formación de las Naciones Unidas, por lo que hay que localizar esta paz exactamente en la mitad de la época de las relaciones intraeuropeas de los jóvenes Estados de la paz interna, que se desarrolló de aproximadamente 1500 hasta casi 1800.

\section{La disolución de la Unión europea medieval y la creación del sistema de San Petersburgo (1772) y Viena (1815)}

Los cambios proyectados hacia la Paz de Westfalia, se realizaron precisamente en la época revolucionaria alrededor de 1800 . El punto de partida fue la gran transformación (Polanyi, 2003, pp. 25 y ss.) de las civilizaciones agrarias a la civilización posagraria (Sieferle, 2009, pp. 1-92), denominada la doble revolución ilustrada e industrial (Hobsbawm, 2005, pp. 9 y ss.); que afectó toda dimensión estatal, social y cultural. En cuanto a la historia universal del Estado, significó la tercera transformación fundamental de la estatalidad que rompió con la monarquía dinástica tradicional (Marquardt, 2009 b, pp. 13 y ss.). Llevó a un nuevo tipo de derecho constitucional, penal y civil según rasgos liberales, racionales y seculares. En este momento, tampoco el derecho de las relaciones internacionales continuó con su antiguo estilo preilustrado y preindustrial, sino que adoptó nuevas lógicas sistémicas.

Lo que sucedió en esta última dimensión, puede caracterizarse como la disolución de la Unión Europea de la Edad media (Marquardt, 2005, pp. 37 y ss., 177 y ss.), llamada la Cristiandad latina, que se había fundamentado en un derecho cultural y zonal de las relaciones interestatales -denominado Ius Publicum Europaeum- y la lógica de la legitimidad histórica acumulada con raíces en los días lejanos de Carlomagno. No se había tratado de un derecho mundial, sino de la normatividad de un sistema de Estados específicos entre los demás, de modo paralelo a los por lo menos, cinco sistemas del universalismo chino, del budismo theravada del sudeste asiático, de los Estados hindúes marathas y de los agrupaciones imperiales alrededor de los Imperios Mogol y Otomano. Este “cuerpo estatal europeo” (Moser, 1777, p. 15) y "república de soberanos" (Federico II de Prusia, 1752, según Quaritisch, 1986, p. 93) había suavizado el belicismo general de las civilizaciones preindustriales, regulando la paz cristiana al estilo de una paz relativa por la prohibición de la usurpación y la intocabilidad de las fronteras sin renuncia del titular, es decir, permitiendo las guerras solo como un mecanismo para imponer derechos negados 
pero plausibles, en el caso más extendido, al estilo de las guerras por la sucesión al trono entre pretendientes que presentaron argumentaciones jurídicas divergentes. De tal manera, se habían evitado realidades extendidas en los Estados asiáticos como las guerras eliminatorias, las ejecuciones de monarcas vencidos, la humillación y esclavización de los perdedores, las amputaciones territoriales salvajes y las usurpaciones al trono.

Cuando estalló la primera ola de revoluciones antisistémicas ilustradas (17761825), el concepto milenario de Europa como una Cristiandad integrada alrededor de un Sacrum Romanum Imperium y una Sancta Romana Ecclesia con numerosas reglas supranacionales limitadoras para el poder estatal, se convirtió en un fenómeno incompatible con el pensamiento secular, mecanicista, atomista, contractualista y soberanista del programa social-newtoniano que pretendió imponerse a la fuerza. Sobre todo, hay que dirigir la mirada al elemento parcial de la revolución de la soberanía (Marquardt, 2009 b, pp. 23 y ss.) que retomó una terminología preexistente, pero fueron precisamente los teóricos republicanos de la revolución francesa, como el Abbé Henri Grégoire (1795), los que siguiendo los principios de la ley natural de Emer de Vattel (1758), consolidaron la soberanía hasta los grados de agudeza y exclusividad propios del siglo XIX (Grewe, 2000, pp. 415 y ss.). Mientras la teoría constitucional se orientó en la libertad del ciudadano, la teoría iusinternacional se enfocó en la libertad de los Estados. La nueva soberanía nacional no toleraba otros dioses al lado de sí mismo.

Por primera vez, el sistema de Estados cristianos, organizado jurídicamente, mostró grandes fisuras en las tres Particiones de Polonia según los Tratados de San Petersburgo de 1772, 1793 y 1795, cuando dos monarquías europeas, a saber, el Sacro Imperio Romano y el ex vasallo polaco de Prusia, en colaboración con el Imperio de Rusia, que por tradición había estado por fuera de la Cristiandad latina, no respetaron más las prohibiciones de la usurpación y de la conquista libre y por meros intereses expansivos, extinguieron el gran Reino de Polonia-Lituania del mapa político. La fuerza motriz fue el Reino de Prusia, que ganó así la independencia completa de sus territorios orientales, la conexión territorial con sus feudos imperiales alrededor de Brandeburgo y el ascenso al círculo de las grandes potencias europeas en lugar de Polonia-Lituania (Davies, 2005, pp. 386 y ss.; Dörr, 1995, pp. 204 y s; Grewe, 2000, pp. 338 y ss.; Lukowski, 1999).

Solo pocos años después, el torbellino de transformación destruyó por completo estas limitaciones de la soberanía en el marco de la gran guerra ideológica por las 
bases de Europa de 1789 hasta 1815 entre los representantes del Iluminismo y los defensores de la Cristiandad. La Francia ilustrada conquistó, con el fin de difundir su nueva religión secular, casi todo el continente; y el general de la revolución $\mathrm{Na}-$ poleón Bonaparte, usurpó en 1804 la corona del Emperador, un hecho impensable en el antiguo régimen. La monarquía primaria de la vieja Europa, el Sacro Imperio Romano Germánico, fue la segunda gran víctima de la nueva lógica de poder al ser descuartizada entre 1803 y 1806 desde fuera en una serie de Estados regionales soberanos como Austria, Baviera, Sajonia y Wurtemberg (Willoweit, 2009, pp. 206 y ss.), que se encontraron, al menos pasajeramente, en el nuevo papel de satélites del ascendente Estado de la Ilustración de París. El pensamiento de la Ilustración tuvo como uno de sus fines la coexistencia de Estados soberanos en relaciones de igualdad absoluta, objetivo que resultaba incompatible con la preeminencia de un Imperio sagrado.

La interacción entre la radicalización de la soberanía y la secularización frente a la perspectiva cristiana, tuvo la consecuencia de que las bases de validez del Jus Publicum Europaeum fueran destruidas: el derecho solo podía fundamentarse, ahora, en la legislación soberana y positiva del Estado Nación, lo cual negaba la posibilidad de un nivel de derecho supraestatal autónomo. En su lugar, entró la débil comunidad del derecho internacional contractual, asociada en la terminología del largo siglo XIX con la comunidad de los autoproclamados Estados civilizados de Europa y las Américas, que fueron totalmente soberanos y se vincularon entre sí únicamente mediante tratados internacionales (Steiger, 2004, pp. 66 y ss.; Ziegler, 2007, p. 186).

De este modo, se dio inicio a una época que el iusinternacionalista alemán Otto Kimminich (1990) ha caracterizado con exactitud por la "anarquía de la soberanía" (p. 74) entre Estados nacionales iguales fuertemente separados. Los Estados civilizados se concedieron mutuamente una autorización a la guerra libre, incluidos los derechos a la conquista, a la anexión y a la destrucción de Estados vecinos. En la época de la anarquía de la soberanía, ya no se imposibilitó según el principio de la legitimidad la creación de nuevos Estados, sino que estos fueron reconocidos según el principio de la efectividad, siempre y cuando no lo impidiera ningún poder más fuerte (Hillgruber, 1998, pp. 21-42).

A partir del Acta del Congreso de Viena de 1815, se inició un gran juego de cálculo de poder en el llamado concierto europeo conformado por la pentarquía de las potencias primarias de Austria, Francia, Gran Bretaña, Prusia y Rusia, las 
cuales se intimidaron mutuamente en el contexto de una especie de guerra fría, denominada balance de poderes (Hillgruber, 1998, pp. 16 y ss.; Steiger, 2004, pp. 59-99). No se puede negar que estas cinco potencias lograron evitar confrontaciones bélicas entre sí, en las dos fases significativas de 1816 a 1852 y de 1872 a 1913, no obstante, en la fase inicial (1772-1815) y en el período final (1914-1945) fueron marcadas por guerras duras entre ellas con fuertes connotaciones ideológicas y competitivas. Aparte de esto, el balance de poderes de la pentarquía se manifestó en un montón de intervenciones y de guerras subsidiarias en la península itálica y los Balcanes, mientras varios Estados pequeños y medianos buscaron su suerte en el campo de batalla por cuenta propia.

En la era de la anarquía de la soberanía, el motivo principal de la guerra ya no fue reclamar un derecho disputado de la sucesión al trono, sino la pura expansión territorial, típicamente legitimada por la perfección de la unidad nacional o la búsqueda de las supuestas fronteras naturales, además de la lucha por zonas industriales y mineras, y la revancha o el ánimo de obtener respeto militar y grandeza. Desde los años 1790, jugó también un papel importante la guerra ideológica, utilizada para difundir o impedir la nueva religión secular del liberalismo ilustrado y su respectivo sistema político, y desde la revolución rusa de 1917, para propagar o evitar el comunismo. La guerra se anarquizó también en sus formas, en vista del nuevo estilo de emplear ejércitos populares y del modo de armamento de la revolución industrial (Müller, 2009, pp. 163 y ss., 212 y ss., 258 y ss.; Neugebauer, 2007, pp. 1 y ss., 296 y ss.).

Es preciso hablar del Sistema de San Petersburgo y de Viena de las relaciones internacionales, válido entre 1772 y 1945 , que la antigua literatura había proyectado erróneamente hasta la Paz de Westfalia de 1648 para buscar legitimidad histórica. Hay que advertir que su verdadero origen se desarrolló entre el Tratado de San Petersburgo de 1772 sobre la primera partición de Polonia y el Congreso de Viena de 1815, con su clímax en las paces vencedoras, nacionalistas, punitivas y humillantes de 1918 a 1920 (Steiger, 2004, p.98; Tomuschat, 2004, pp. 395 y ss.), para ser reemplazado en 1945 por el régimen de la paz mundial de las Naciones Unidas.

\section{Panorama empírico de los cambios territoriales violentos}

Como consecuencia de lo anterior, no hubo otra fase de la historia europea que la de los 174 años que van de 1772 a 1945, en la que se puedan encontrar 
más fenómenos violentos y radicales asociados a cambios de las fronteras estatales, a la desmembración o la eliminación de Estados y a la fundación de nuevos Estados desprovistos de tradición. Esta situación afectó prácticamente a todos los Estados europeos con la excepción de Portugal. Las tablas 1 y 2 presentan una visión panorámica sobre los cambios territoriales de la época de la anarquía de la soberanía (Dörr, 1995, pp. 204-270, 309-322, 327-354; Kinder y Hilgemann y Hergt, 2012, pp. 11-241; Truyol y Serra, 1998, pp. 105 y ss.). Se distingue entre las transformaciones primarias del sistema de Estados europeos, dieciocho en total, y las veintiséis transformaciones secundarias, respectivamente. 


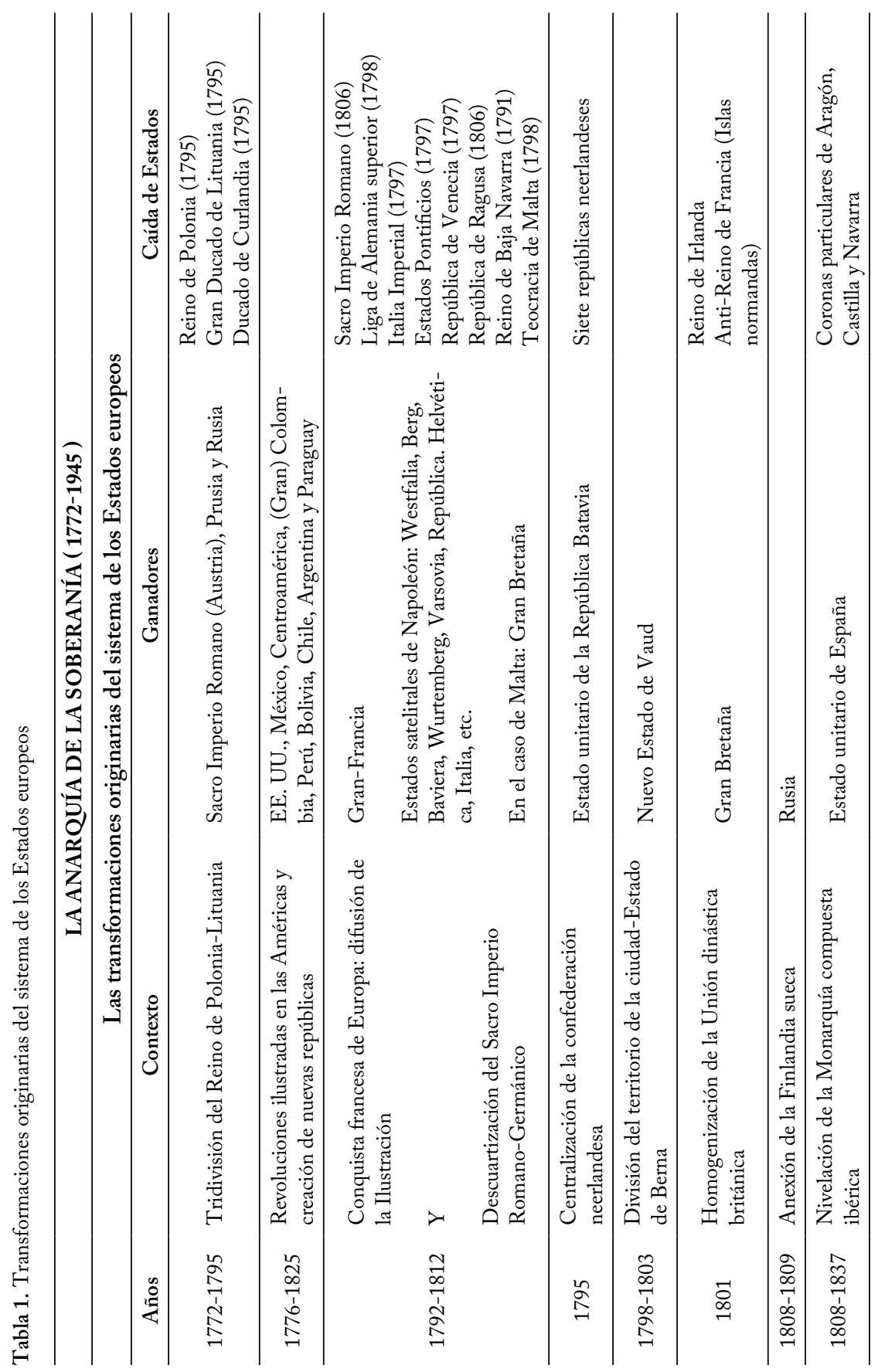




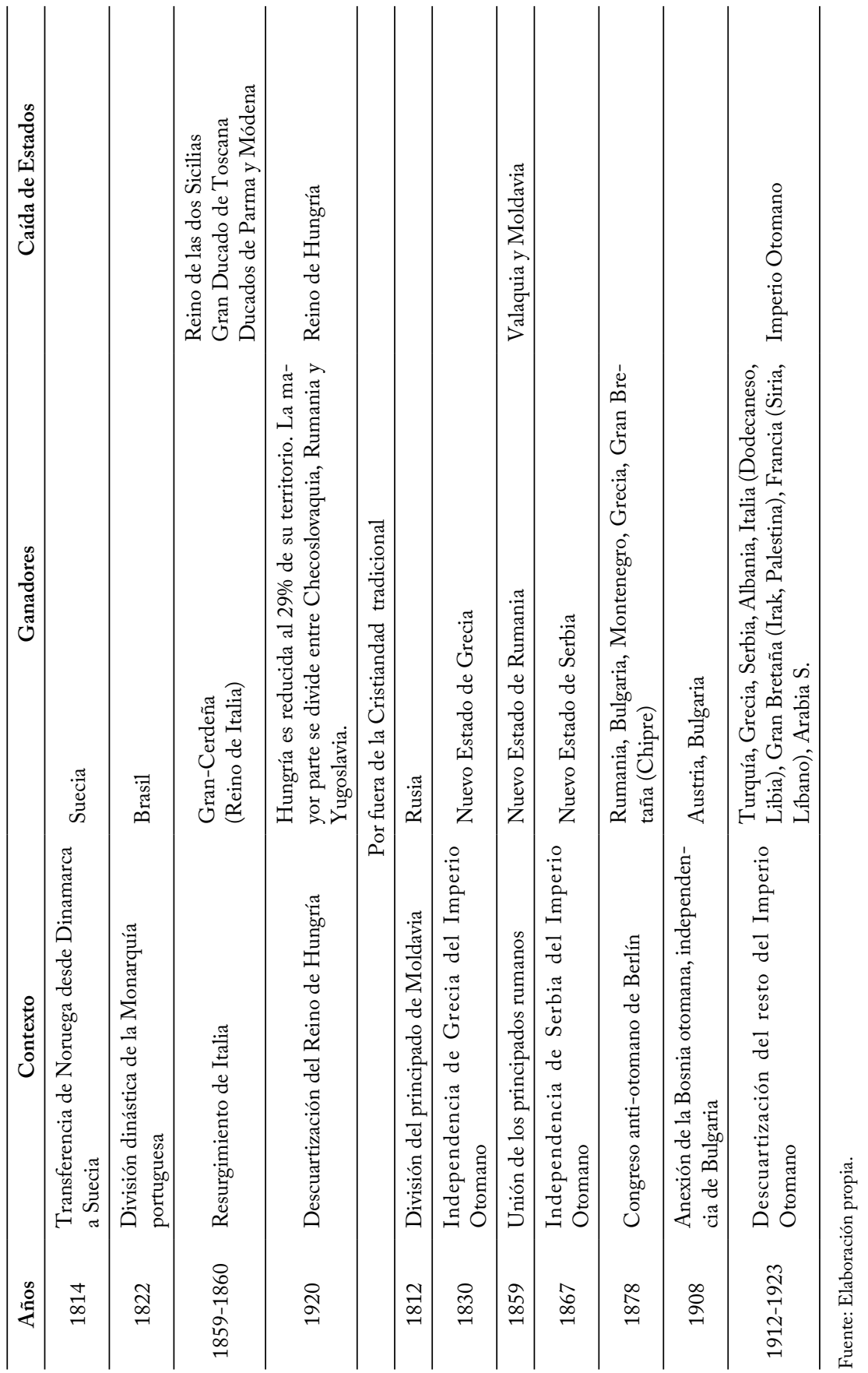




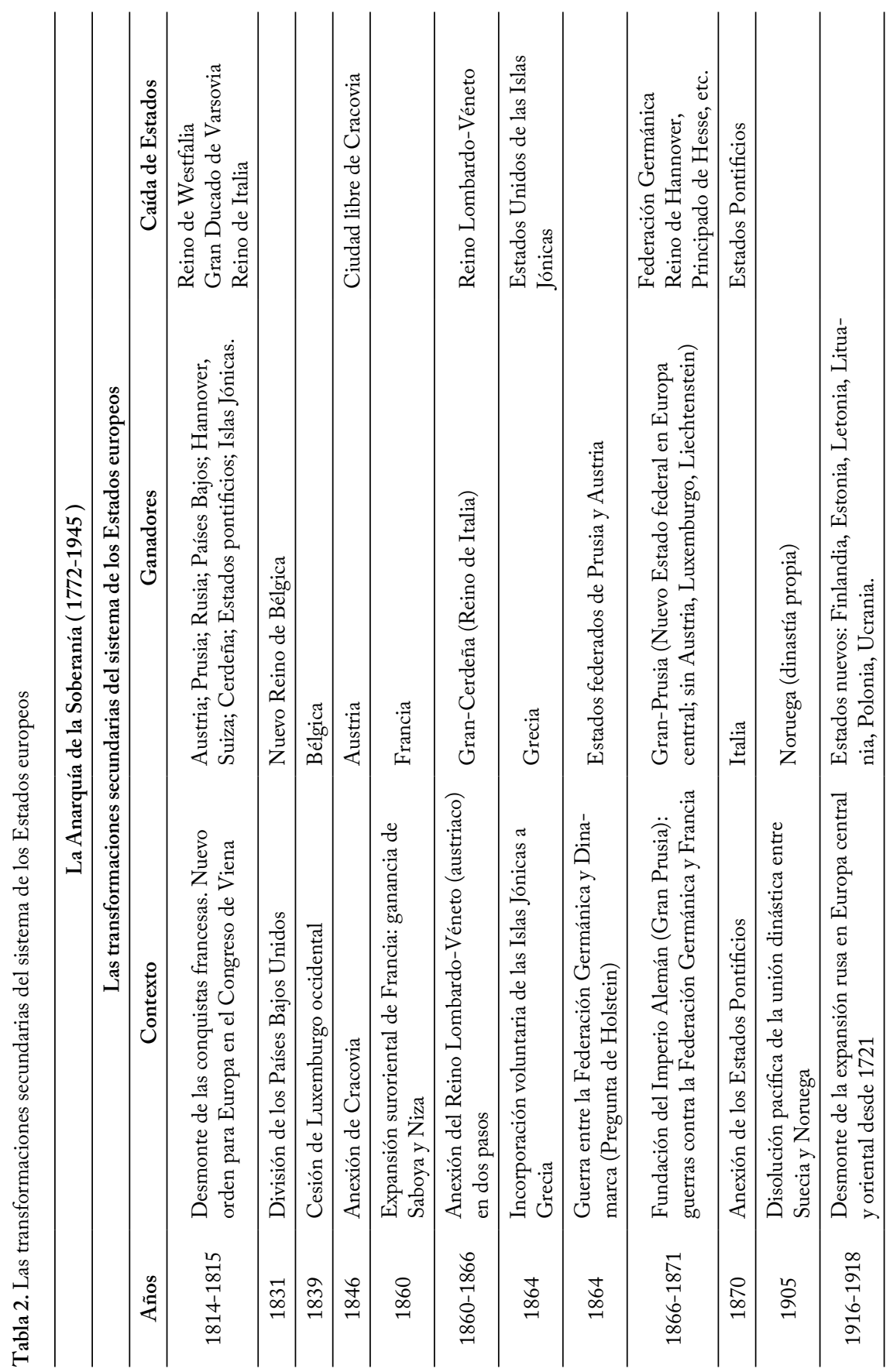




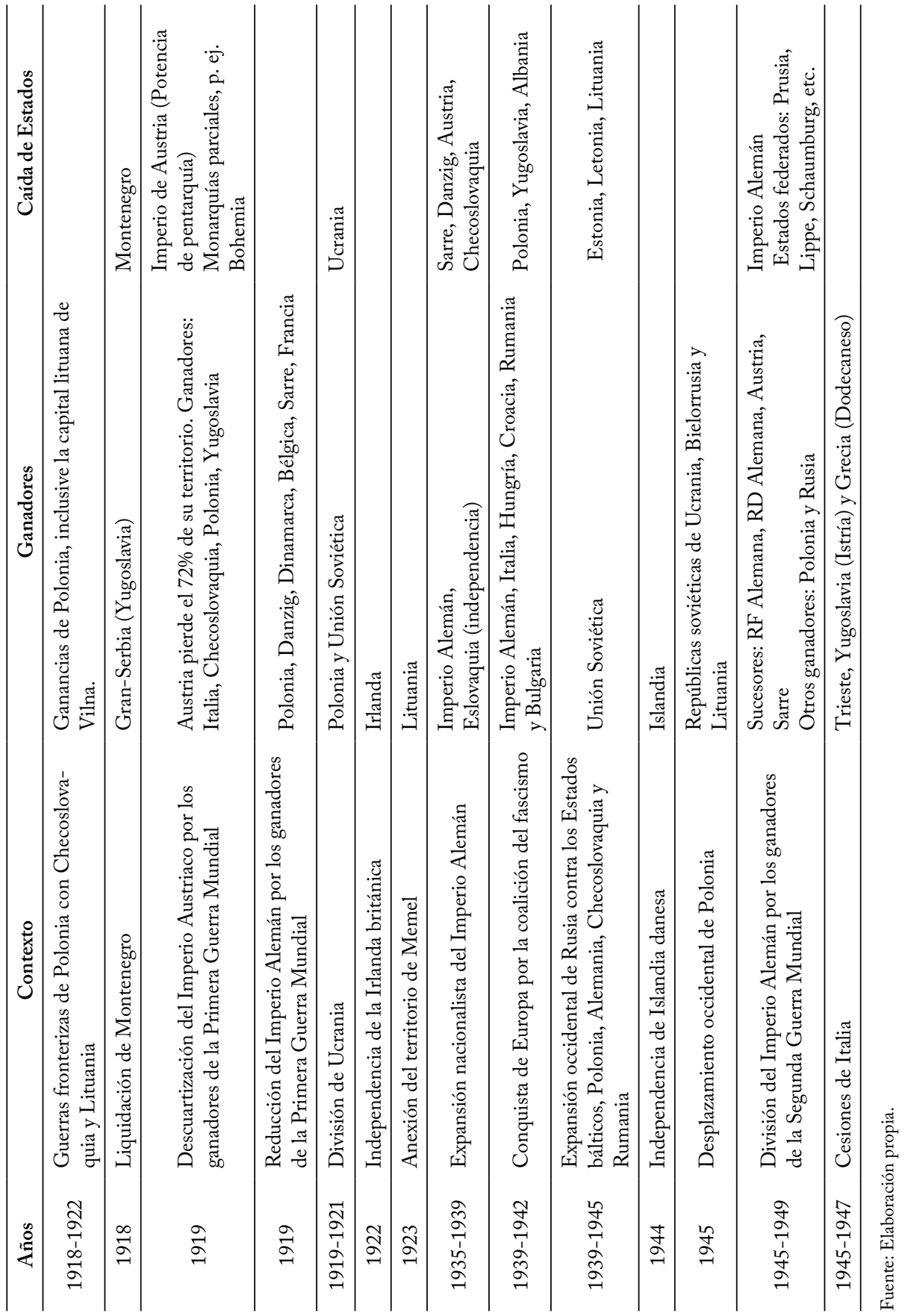


En las tablas 1 y 2 se cuentan, entre 1795 y 1945, más de 50 exterminaciones de Estados, de los cuales algunos fueron destruidos varias veces. Se incluyeron cuatro descuartizaciones de Estados grandes, a saber, la del Sacro Imperio Romano Germánico (1806), la del Imperio de Austria (1919), la del Reino de Hungría (1920) y la del Imperio Otomano (1912-1923), así como una tridivisión, la del Reino de Polonia-Lituania $(1772,1795)$.

Una de las zonas más afectadas fue el hasta entonces Sacro Imperio Romano Germánico en Europa central. En la primera etapa, el general de la revolución francesa Napoleón Bonaparte desmembró, entre 1803 y 1806, el tradicional Imperio en cuatro bloques, creando el Imperio Austriaco, la Confederación del Rin, el Reino de Prusia y los territorios incorporados a Francia, lo cual continuó así hasta la Batalla de las Naciones de Leipzig de 1813. Después existió otra vez, por medio siglo, un orden casi completo del antiguo territorio imperial en la forma de la Federación Germánica, liderada por Austria, aunque en una nueva estructura de los Estados federados y con un nivel central más débil (1815-1866). Las guerras de Prusia contra la Federación Germánica en 1866 y contra Francia en 1870, llevaron a la fractura más profunda de la historia centroeuropea, eliminando a cuatro Estados, inclusive al Reino de Hannover, y creando en contra de la tradición del Sacro Imperio Romano Germánico una división en dos imperios soberanos, a saber, el Imperio Austriaco y el Imperio Alemán, el cual fue, precisamente, una federación intermonárquica, controlada por el Reino de Prusia (Doering-M., 2001; Kotulla, 2008, pp. 289-554; Nipperdey, 1985, p. 791; Mann, 2008, pp. 316 y ss.; Wehler, 1995, pp. 293 y ss.; Willoweit, 2009, pp. 204 y ss., 229 y ss., 258 y ss.). Siguieron otros cambios significativos de las fronteras centroeuropeas por los Tratados de Versalles y Saint Germain de 1919, la Reincorporación del Saar en 1935, el Anschluss austriaco y los Acuerdos de Múnich de 1938, las anexiones de 1939, la Conferencia de Potsdam de 1945 y la división de 1949, hasta que la estructura territorial se estabilizó definitivamente en 1990 con el Tratado «dos más cuatro» sobre el acuerdo final con respecto a Alemania (Dörr, 1995, pp. 248 y ss., 327 y ss., 376 y ss., 399 y ss.; Willoweit, 2009, pp. 321 y ss., 408 y ss.).

\section{La otra cara de la anarquía de la soberanía: los genocidios del Estado nación}

La anarquía de la soberanía también dirigió su potencial de violencia hasta el espacio interno de los Estados nacionales, en esferas que se interpretaron en ese 
entonces como asuntos internos, pero que entrarían hoy en día en la categoría de delitos internacionales. Cuando el Estado nación -un verdadero hijo de la revolución francesa- intentó homogenizar la diversidad de los súbditos señoriales del antiguo régimen, se efectuaron políticas de la estandarización lingüística escolar y medial, y limpiezas étnicas y genocidios. No se quiere entrar a la trampa de pretender evaluar hechos históricos de modo jurídico según normas actuales, pero no hay dudas sobre la enorme concentración de hechos del respectivo tipo entre 1845 y 1948.

Como primer ejemplo, se menciona el Reino de Gran Bretaña, que abusó entre 1845 a 1849 de la Gran Hambruna Irlandesa, causada socio-ecológicamente por el ataque microbiológico a una monocultura de papas, y que dejó morir a un millón de celtas indeseados mediante el rechazo sistemático del apoyo posible y obligatorio (Boyle, 2010; Mann, 2006, p. 61), mientras se efectuó la expulsión de los gaélicos de Escocia en forma de los highland clearances mediante el permiso a los latifundistas ingleses de apropiarse sistemática y violentamente de las tierras campesinas para criar ovejas, de modo que la población celta tuvo que emigrar a América (Richards, 1985). Sin embargo, fue aun más excesiva la violencia étnica, cometida por poderes estatales, en la disolución de los grandes imperios multiétnicos en varios Estados naciones artificiales y ahistóricos: la muerte del Imperio Otomano entre 1878 y 1923 , llevó a la expulsión de grandes partes de los musulmanes de los Balcanes (Calic, 2010, p. 67) y de los cristianos de Asia menor, inclusive el genocidio en los armenios (Gerlach, 2010, pp. 92 y ss.; Naimark, 2001, pp. 17 y ss.), mientras la ejecución ex post de la muerte del Sacro Imperio Romano y del Imperio Austrohúngaro se manifestó en aproximadamente 15 millones de alemanes étnicos expulsados y otras intervenciones graves en la estructura étnica de la zona, en el marco de construir Estados naciones étnicamente homogenizados (1945-1948) (Naimark 2001, pp. 114 ss.; Rummel 1997, pp. 297 y ss.). De igual forma, hay que mencionar el caso del Estado nación neo-europeo de Israel, porque la creación artificial de 1948 en manos de emigrantes judíos, donde predominaron europeos, fue acompañada por la expulsión de grandes partes de la población árabe de Palestina (Pappe, 2011, pp. 1 y ss.). No obstante, el genocidio más excesivo se realizó en la política bélica internacional del Imperio Alemán que aniquiló aproximadamente a dos tercios de los judíos europeos (1941-1945) (Mann, 2006, pp. 180 y ss.). La lista no es completa, pero indica una enorme concentración de fenómenos violentos masivos de poderes estatales soberanos sin precursor ni sucesor. 


\section{Acercamiento a una explicación}

Resulta importante contextualizar el aumento significativo de la violencia internacional en el preludio de la pacificación fundamental del mundo. Se quiere dirigir la mirada a los siguientes diez factores.

Primero, ningún Estado de la era de transformación actuaba con una consciencia de ilicitud, sino que se percibía a sí mismo como un combatiente heroico en nombre de valores superiores, bajo la elevación inconsciente de la ética heroica de la clase guerrera del antiguo régimen a la lógica de confrontación entre naciones soberanas que ahora creían en un supuesto deber de defender el honor de la respectiva patria. Segundo, la psique humana y social mostraban grandes dificultades en internalizar la gran transformación acelerada desde la civilización agraria hasta la civilización industrial, lo que significaba profundas confusiones, deformaciones, alienaciones y pérdidas de valores, sin poder anclar y estabilizar con la misma velocidad los nuevos valores.

Tercero, los paradigmas atomistas y competitivos del social-newtonianismo ilustrado, motivaban a entender también las relaciones internacionales como un juego de libre competición, sin ser restringido por tradiciones de moderación declarados como revestidas a la antigua. Cuarto, el paradigma de la soberanía nacional y del nacionalismo, proveniente de la revolución francesa, provocaba auto-percepciones colectivas que entendían los supuestos intereses nacionales - por ejemplo, defenderse frente a una ofensa o perfeccionar las fronteras según argumentaciones etnohistóricas- como superior a todo, divinizando a la propia nación soberana según los superlativos de aquella teoría que Bodin había formulado para honrar a su monarca.

Quinto, el paso de la guerra intermonárquica con ejércitos de mercenarios, a la guerra nacional con ejércitos populares del servicio militar, obligatorio a los ciudadanos masculinos adultos, contribuía a identificar como enemigo exterior no solo a las fuerzas armadas del Estado vecino, sino a su pueblo completo. Sexto, eran decisivas la burocracia y la tecnología industrial, que abrían nuevas dimensiones de una eficiencia mortal y que en simultáneo distanciaban y anonimizaban la relación de percepción entre victimario y víctima. Séptimo, la actuación estatal según las formas jurídico-administrativas acostumbradas, tenían el efecto de que los funcionarios y soldados se autoestimaban como legitimados y obligados, también si el orden concreto se enfocaba en el peor crimen estatal. 
Octavo, la época de la gran transformación era un periodo de grandes confrontaciones sistémicas entre fines ideológicos sacralizados: el liberalismo republicano quería imponerse a la fuerza en las guerras de transformación de 1790 a 1815, de 1914 a 1918 y de 1939 a 1945, el comunismo seguía entre 1917 y 1950 y también el fascismo lo intentaba en las décadas de 1930 y 1940, y todo sucedía bajo un perfil secular-religioso al estilo de un combate final sobre la única verdad absoluta.

Noveno, el Estado nación de la primera mitad del siglo XX se basaba en nuevas élites que habían ascendido rápidamente desde las clases bajas hacía el núcleo de poder, sin haber internalizado la moderación típica de una élite gubernamental establecida. Décimo, de modo paralelo continuaban en el liderazgo militar antiguas élites que todavía creían en guerras heroicas y caballerescas sin percibir que sus órdenes estratégicas acostumbradas podían desarrollar, en la era de las armas industriales, efectos monstruosos.

En síntesis, en la era de la gran transformación se mezclaban nuevas y antiguas lógicas creando una combinación explosiva y peligrosa. El Estado nación soberano con ejércitos populares y armas industriales en sus manos, se convertía en un vecino peligroso para su entorno que, por supuesto, se compuso por actores del mismo tipo e igual peligrosidad. En la retrospección de las generaciones posteriores a 1950, quedó la imagen insistente de que el Estado padre podía degenerarse hasta el criminal más cruel, capaz de hacer todo lo abominable que su propia ley penal evaluaba éticamente reprochable.

\section{La mundialización: del ius publicum europaeum al \\ Derecho de la comunidad de los Estados civilizados}

Un elemento importante de la disolución de la Unión Europea de la Edad media, debe verse en la pérdida de los contornos del ius Publicum Europaeum hacia el exterior. No solo se formaron en el inicio del largo siglo XIX, el mismo número de Estados neo-europeos en las Américas, como los Estados Unidos (entre 1776-1787), México (en 1821), Colombia (en 1819) y Brasil (en 1822) (Grewe, 2000, pp. 497 y ss.; Hillgruber, 1998, pp. 21-42; Truyol y Serra, 1998, pp. 106 y ss.), sino que también se asimilaron el ortodoxo Imperio de Rusia y los cinco Estados sucesores del Imperio Otomano con una orientación cristiana-oriental en los Balcanes, por ejemplo Grecia (desde 1830) y Bulgaria (en 1908). 
Fue aún más simbólico que en la Paz de París de 1856, las potencias unidas de Europa invitaran a su contrincante tradicional, el Imperio Otomano, "a la participación en las ventajas de la comunidad europea de Estados y del derecho público europeo" (art. 7; Bluntschli, 1872, p. 61; Bogdandy y Hinghofer-Szalkay, 2013, pp. 226 y ss.; Ziegler, 2004, pp. 361 ss.). La creciente universalización del sistema europeo es bien visible en la ratificación del Convenio de Ginebra, para Aliviar la Suerte de la Condición de los Heridos de los Ejércitos en Campaña de 1864, pues se incluyó en 1865 al Imperio Otomano, en 1867 a Rusia, en 1874 a Persia, en 1886 a Japón, en 1895 a Siam (Tailandia) y en 1904 a China. Nada de esto fue un proceso voluntario, sino un fenómeno fundamental de poder a causa de la ventaja fundadora de Europa en la gran transformación industrial y la posesión originaria de las respectivas armas irresistibles. Originalmente, todas las potencias asiáticas intentaron resistir, pero después de las derrotas en las Guerras de Opio (1839-1842, 1856-1860) y en la Guerra Bóxer (1900), incluso el Imperio de China se vio tan humillado que las élites empezaron a adoptar conceptos europeos del Estado y de las relaciones internacionales para salvar la existencia propia (Eglauer, 2005, pp. 12 ss.). En otras palabras, se disolvieron los sistemas internacionales del universalismo chino, del budismo theravada, de los Estados hindúes marathas y de los agrupaciones imperiales alrededor de los Imperios Mogol y Otomano. Pero también la particularidad europea se disolvió, pues el derecho eurodescendiente se globalizó al derecho de los Estados civilizados y posterior international law.

Además, el largo siglo XIX fue aquella época en la que un grupo de potencias europeas, en especial Gran Bretaña, Francia y Rusia, y secundariamente Alemania, Italia, Bélgica y otras, usaron los irresistibles medios de poder de la revolución fósil-energética-industrial para conquistar gigantescos imperios globales. Cada uno de estos imperios fue más grande que la Cristiandad latina del antiguo régimen. En 1910, el pionero de la revolución industrial, Gran Bretaña, gobernó, directa o indirectamente, el 20\% de la tierra y el 23\% de la población mundial (Ferguson, 2003; Hobsbawm, 2001, pp. 66 y ss.; Kinder y Hilgemann y Hergt, 2012, pp. 110116). En vista del predominio del precursor industrial en el sistema internacional, el iusinternacionalista Grewe (2000) califica el siglo entre 1815 y 1919 como el siglo inglés de la historia de las relaciones internacionales (pp. 429-574). No obstante, se trató de emanaciones y aceleradores de la gran transformación del planeta, que brillaron durante una o dos generaciones, pero por fuera de toda opción de estabilizarse de manera duradera. 
Mientras en 1775 la Europa latina había sido solo una civilización sectorial al lado de china, la india, la otomana, etc., en 1914 Europa ejercía su hegemonía en el mundo. En una época sin precedentes, en la que los Estados industriales europeos gobernaron hasta el noventa por ciento de la tierra, se disolvió automática e inevitablemente la idea de la unidad de marco europea, que resurgiría en forma significativa de manera paralela a la disolución de estos imperios globales de corta vida después de 1945.

\section{La excepción zonal: la paz interamericana}

La excepción notable de la anarquía de la soberanía del largo siglo XIX, puede reconocerse en las repúblicas neo-europeas de las dos Américas. Aunque resulta exagerada la teoría idealista de las relaciones internacionales que sostiene que no hay guerras entre democracias (Herdegen, 2005, pp. 61 y s; Münkler, 2005 b, p. 143; Pinker, 2011, pp. 278 ss.), teniendo en cuenta por ejemplo, la guerra de conquista de los Estados Unidos contra México para ganar nuevos territorios de la colonización anglófona (1846 - 1848) o la Guerra del Salitre de Chile contra Bolivia y Perú (1879 - 1884) por los recursos mineros del Desierto de Atacama que prometían ricas ganancias de exportación; no hay duda de que en el doble continente americano republicano se dieron mucho menos guerras internacionales que en la Europa monárquica, lo cual tuvo como consecuencia una estabilidad mucho más alta de las fronteras estatales. En 1890 la Primera Conferencia Panamericana adoptó la siguiente resolución: "El principio de conquista queda eliminado del Derecho público americano. [...] Las cesiones de territorio [...] serán nulas [...]”. Esta negación de la anarquía de la soberanía interestatal se convirtió, después de 1945, en una característica del régimen de las Naciones Unidas, aspecto sobre el cual se volverá en la segunda parte de este artículo.

\section{Segunda parte: la gran pacificación y el Estado posbélico en la comunidad de la paz mundial}

\section{Ius contra bellum: la prohibición general del uso de la fuerza (1945) y el final de las guerras de conquista (1967)}

Un hecho fundamental de la historia contemporánea lo representa la integración de los Estados del planeta en un orden global de la paz que rompe profundamente 
con la anarquía de la soberanía del Sistema de San Petersburgo y Viena de 17721815. Se ha mundializado el concepto de paz por derecho, bajo algunas similitudes estructurales con la Paz eterna en la tierra del Sacro Imperio Romano de 1495-1555. En los orígenes puede reconocerse una manifestación de la paz acordada, no de la paz impuesta unilateralmente, aunque el pacto incluyó mecanismos de imposición, similar a su modelo histórico.

La clave fue la prohibición general de la guerra en el derecho internacional público, acordada por primera vez en 1928 en París por el Pacto Briand-Kellogg entre quince Estados. En 1945, fue perpetuada y fortalecida por la Carta de las Naciones Unidas en la forma de la prohibición general de la amenaza y del uso de fuerza contra otro Estado (art. 2 núm 4; Gareis y Varwick, 2005, pp. 58 y ss., 80 y ss.; Grewe, 2000, pp. 619 y ss., 639 y ss., 673 y ss.; Herdegen, 2005, pp. 23 y ss., 246 y ss.; Hobe y Kimminich, 2004, pp. 48-51, 306-341; Kokott, 2000, p. 9; Monroy Cabra, 2002, p. 254; Nussberger, 2010, pp. 65 y ss.). En paralelo, se garantizó la integridad territorial de los Estados. De tal manera el ius ad bellum del Estado soberano se convirtió en un ius contra bellum (Bothe, 2010, p. 645; Grewe, 2000, p. 673). Si se pretende entender el ius ad bellum como la característica clave de la soberanía, los Estados perdieron por la adhesión originaria a las Naciones Unidas su soberanía externa clásica, la última vez, en el caso suizo en 2002. Simultáneamente, algunos Estados prohibieron constitucionalmente la guerra de agresión, así Japón en 1946 (art. 9), Italia en 1947 (art. 11), Alemania occidental en 1949 (art. 26) y Bolivia en 2009 (art. 10), mientras Colombia promulgó en 1991 un derecho a la paz (art. 22). Además, las Naciones Unidas limitaron la anarquía de la soberanía por la Convención para la prevención y la sanción del delito de genocidio de 1948 que transformó supuestos asuntos internos de los Estados en delitos internacionales (Hobe y Kimminich, 2004, p. 253). En cierto sentido, la universalización de las garantías individuales del derecho constitucional hizo de los súbditos de los Estados naciones una especie de ciudadanos mundiales (Nussberger, 2010, p. 86). La pacificación fundamental es una de las grandes rupturas sistémicas de la historia universal. A pesar de que la misma es mucho más que mera lírica normativa, se trata de uno de los éxitos que se subestima con frecuencia.

En los años 1950 a 1953, las jóvenes Naciones Unidas realizaron la primera ejecución de la paz mundial contra un agresor, el Consejo de Seguridad la declaró, por la Resolución 85, a Corea del Norte a causa de la invasión en el Estado hermano del sur (Grewe, 2000, pp. 673 y s; Hattenhauer, 1999, p. 754; Hobe y 
Kimminich, 2004, p. 132), mientras la paralela conquista de la retirada teocracia del Dalai Lama del Tíbet por China quedó como el último caso de la historia universal sin crítica de la comunidad internacional de Estados (Dörr, 1995, pp. 363 y ss.; Herdegen, 2005, p. 190). Como los éxitos más recientes de disciplinamiento de Estados agresivos, se pueden nombrar la derogación de la invasión de Irak en Kuwait en 1991 (Hestermeyer, 2004, pp. 327 y s), la protección de la nueva república de Bosnia-Herzegovina contra el Estado de facto de Srpska entre 1992 y 1996 (Calic, 2010, pp. 311 y ss.; Hobe y Kimminich, 2004, 336; Kaldor, 2012, pp. 32-70) y la salvación de la independencia de Timor Oriental contra un cuarto siglo de la ocupación por Indonesia en 2002 (Vickers, 2005, pp. 138, 167, 180, 229). Las Naciones Unidas han realizado desde los inicios en Palestina en 1948 y en Cachemira en 1949, un total de 67 misiones de paz con fuerzas de paz, especialmente en el sur de Asia, en los Balcanes, en Centroamérica y en el África subsahariana; entre estas más de dos tercios en la verdadera fase de ascenso desde 1990 (Gareis y Varwick, 2005, pp. 89 y ss.; Grewe, 2000, p. 674; Herdegen, 2005, pp. 330 y ss.; Hobe y Kimminich, 2004, pp. 333 y ss.).

El éxito más visible del ius contra bellum puede reconocerse en el hecho de que las guerras de conquista contra Estados vecinos dejaron de ser realizables: el último éxito territorial de la historia universal, lo tuvo en 1967 el Estado de Israel al invadir en la Guerra de los Seis Días los lugares de su afirmado origen histórico varios milenios antes. Sin embargo, Israel ha anexionado formalmente solo Jerusalén oriental (1980) y los altos de Golán (1981), mientras ha establecido en Cisjordania y en la Franja de Gaza un régimen de ocupación provisoria durante casi medio siglo, calificado distintas veces como ilegal por resoluciones del Consejo de Seguridad de las Naciones Unidas: 242 de 1967, 478 de 1980 y 497 de 1981 (Pappe, 2006, pp. 183 ss.; Yaron, 2008, pp. 172 y s). A los escenarios probables ya no pertenece la incorporación definitiva -en vista del Acuerdo de Oslo de 1993 sobre un gobierno palestino autónomo, de la retirada militar de Gaza (2005) y del reconocimiento de la estatalidad propia de Palestina por la ONU (2012)-, aunque tampoco es sostenible el así perpetuado régimen del apartheid entre ciudadanos y no-ciudadanos (Azoulay y Ophir, 2013, pp. 25 y ss.). De todos modos, la Barrera israelí de Cisjordania, construida desde 2003 sobre aproximadamente 700 kilómetros, sigue en grandes partes una línea por dentro de Cisjordania y prepara, de tal manera, futuras anexiones parciales en beneficio de asentamientos israelíes. En 2004, la misma fue declarada ilegal por la Corte Internacional de Justicia (Nussberger, 2010, p. 83). 
Otro candidato de una de las últimas anexiones de la historia mundial, es el pequeño Reino de Sikkim en el Himalaya, incorporado en 1975 como un Estado federado a la Unión de la India, pero existió ya antes un título de protectorado y hubo la legitimación adicional por un referendo (Dörr, 1995, pp. 387 y ss.). Además, Vietnam del Sur fue integrado, en 1976, a Vietnam del Norte, pero se trató más de una reunificación, declarada por el último gobierno revolucionario del sur después de varios decenios de división en el marco de la Guerra Fría (Dörr, 1995, pp. 390 ss.). Posteriormente, no se encuentra ningún caso adicional de una expansión bélica (Zacher, 2001, pp. 215-250).

La garantía de la integridad territorial del articulo 2 número 4 de la Carta de la ONU imposibilitó la expansión militar de Estados, pero dejó espacio para la autodeterminación de los pueblos que se menciona también en dicha Carta (art. 1 núm. 2 y art. 55; Herdegen, 2005, pp. 272 y ss.; Hobe y Kimminich, 2004, pp. 111 y ss.). Las Naciones Unidas aceptaron la mayor parte de las desmembraciones y secesiones de Estados que siguieron, según el principio uti possidetis iuris, a subdivisiones federales o administrativas, así en la retirada europea del África (1957-1977) y en la reorganización de los Estados plurinacionales en Europa oriental y Asia central (1990-2006). El hecho de que se aceptó en 1993 la independencia de Eritrea de Etiopía, mientras se ha ignorado desde 1991 la del país vecino de Somalilandia de Somalia, subraya ciertas márgenes de arbitrariedad. De todos modos, según el artículo 4 número 1 de la Carta de la ONU de 1945 los admitidos tuvieron que ser "Estados amantes de la paz" (Grewe, 2000, pp. 659 y ss.).

De igual forma, quiere señalarse el éxito del ius contra bellum en forma de la desaparición completa de confrontaciones bélicas entre las grandes potencias militares de la primera categoría a partir de 1945 -o por lo menos después de 1953, si ya sería posible calificar a China en la Guerra de Corea como una potencia mundial-. Asimismo, terminaron por completo las guerras entre Estados industrializados del primer nivel de desarrollo. En la década de 1970 pueden comprobarse algunas pocas intervenciones humanitarias de Estados de medio peso -en particular la de India frente al democidio en Pakistán oriental (Bangladés, 1971) y la die Vietnam para parar el régimen democidial de los Jemeres Rojos en Camboya (1978)- donde nadie puede negar los respectivos hechos de lesa humanidad, pero ante la claridad del ius contra bellum de la Carta de la ONU, quedaron ilegales los actos militares en mención (Monroy Cabra, 2002, pp. 258-259; Tomuschat, 2008, p. 68). Los críticos de la perspectiva positiva, anotan esto como una falta de eficacia de un 100 
$\%$ en la paz mundial. Sin embargo, aunque nadie puede negar la persistencia de infracciones del ius contra bellum, sería equivoco cerrarse a la perspectiva, a largo plazo, que muestra indudablemente la implosión masiva de la actividad bélica en los decenios de la ONU. La mayor parte de los conflictos armados contemporáneos no estallan entre Estados soberanos, sino que se trata de guerras civiles y nuevas formas de una violencia sub-bélica en el interior de varios Estados débiles, especialmente en África y Asia (Fisas, 2006, pp. 48 y ss.).

Recapitulando, la anarquía de soberanía del largo siglo XIX se ha extinguido en el marco de una organización cooperativa de todos los Estados del planeta y de la estandarización rudimentaria del derecho público de paz a nivel global. En la época de las Naciones Unidas, la soberanía externa del Estado no significa más el derecho a la guerra, sino el ser sujeto inmediato del derecho internacional público en el marco de la igualdad de todos los Estados. Casi no existen diferencias legales entre superpotencias como Estados Unidos y enanos como Liechtenstein, a pesar de que hay que anotar desigualdades parciales en beneficio de los cinco aliados vencedores de la Segunda Guerra Mundial-EE. UU., Rusia, Gran Bretaña, Francia y China- pues ellos ocupan los únicos puestos hereditarios en el Consejo de Seguridad de las Naciones Unidas y monopolizan la posesión legal de armas nucleares.

\section{La justicia de la paz mundial}

Similar al modelo de la Paz eterna en la tierra, el ius contra bellum de las $\mathrm{Na}$ ciones Unidas se caracteriza como un orden de la justicia de la paz mundial que pretende reemplazar la guerra por la decisión obligatoria del juez. El núcleo es la Corte Internacional de Justicia, establecida en 1945 en La Haya. Un total de 70 Estados han aceptado la sumisión bajo la jurisdicción obligatoria: México en 1947, Suiza en 1948, India en 1974, España en 1990, Canadá en 1994, Australia en 2002, Gran Bretaña en 2004, Japón en 2007 y Alemania en 2008, pero faltan potencias importantes como EE. UU. (retirada en 1986), Francia, Rusia y China.

Aparte de varias sentencias sobre fronteras y derechos de la pesca marítima, han llamado la atención varias decisiones y dictámenes como la protección de Nicaragua frente a la intervención estadounidense (1984), la probabilidad de la ilegalidad del uso de armas nucleares (1996), la ilegalidad de la barrera israelí de Cisjordania, el reconocimiento del genocidio en Bosnia (2007), la confirmación de la declaración de independencia de Kosovo (2010) y la defensa de la inmunidad de los Estados 
frente a la jurisdicción nacional de otros Estados (2012) (Hobe y Kimminich, 2004, pp. 553-568; Nussberger, 2010, pp. 78-85).

De modo paralelo, se penalizaron supraestatalmente los crímenes de guerra, los crímenes de lesa humanidad, el genocidio y la agresión contra la paz. El desarrollo del derecho penal internacional se preparó entre 1945 y 1948 y ganó sus contornos en los años 1990, con el efecto de que los jefes de Estado o de gobierno, responsables de dichos delitos, no pudieron confiar más en no ser juzgados personalmente ante un tribunal internacional. Entre los primeros ejemplos prominentes, se encuentran la causa del ex jefe de gobierno y dictador japonés Hideki Tōjō (1941-1944), ejecutado por ahorcamiento en el contexto de los Juicios de Tokio en 1948, y la condenación del último presidente de la Alemania nacionalsocialista Karl Dönitz (1945), castigado en los Juicios de Núremberg en 1946 con diez años de prisión (Hattenhauer, 1999, pp. 737 y ss.; Hobe y Kimminich, 2004, p. 252; Kaleck, 2012, pp. 17 y ss.; Laughland, 2008, pp. 103 y ss.; Nussberger, 2010, pp. 110 y ss.). Mientras estos tribunales interaliados fueron todavía criticados como una supuesta justicia del vencedor para fortalecer la victoria de los aliados en la guerra mundial -todos los jueces vinieron de los aliados y todos los castigados de los vencidos- empezó en la década de 1990 una ola de procesos políticos ante tribunales internacionales ad hoc, creados por las Naciones Unidas para evaluar el respectivo contexto histórico-político concreto. Pueden indicarse: primero, la causa del primer ministro de Ruanda Jean Kambanda (1994), condenado en 1998 a cadena perpetua por el genocidio sobre los tutsis; segundo, el presidente de Serbia Slobodan Milošević (1989-2000), acusado en 1999 por crímenes en tres guerras, pero fallecido en 2006 en la prisión preventiva; tercero, el ex dictador de Liberia Charles Taylor (1997-2003), condenado en 2012 a 50 años de prisión por crímenes de lesa humanidad en la guerra civil en el país vecino de Sierra Leona; cuarto, el ex jefe de Estado de Camboya Khieu Samphan (1976-1979), que desde el 2010 se justifica judicialmente por el democidio de los Jemeres Rojos; quinto, el ex presidente del Estado de facto de Srpska en los Balcanes Radovan Karadžić (1992-1996), arrestado desde el 2008 en La Haya como el presunto responsable de varios asesinatos en masa, especialmente en 1995 en Srebrenica (Dyrichs, 2008, pp. 81 y ss.; Hobe y Kimminich, 2004, pp. 256 y ss., 265 y ss.; Kaleck, 2012, pp. 53, 59 y ss.; Laughland, 2008, pp. 207, 221 y ss.; Nussberger, 2010, pp. 113 y ss.).

Ante la Corte Penal Internacional en La Haya, establecida por el Estatuto de Roma de 1998 y reconocida hasta ahora por 122 Estados -sin EE. UU., Rusia, 
China, India e Israel-, se ordenó por primera vez en el 2009 una detención contra un presidente en cargo, Omar al-Bashir del Sudan (desde 1989) por el genocidio en Darfur. En 2011, el mismo tribunal ha arrestado el ex presidente Laurent Gbagbo de Costa de Marfil por crímenes de lesa humanidad (Hobe y Kimminich, 2004, pp. 259-264; Kaleck, 2012, pp. 101 y ss.; Nussberger, 2010, pp. 115 y ss.).

Paralelamente, las justicias nacionales empezaron a perseguir penalmente la tiranía mortal de sus peores gobernantes (Laughland, 2008, pp. 175 y ss.), desde el proceso contra el ex dictador griego Georgios Papadópoulos en 1975, pasando por el Juicio a las Juntas de Argentina (1985), la causa del ex dictador etíope Haile M. Mengistu (2007), la del expresidente peruano Alberto Fujimori (2009), la del exdictador uruguayo Juan M. Bordaberry (2010) hasta la del expresidente egipcio Hosni Mubarak (2012).

\section{Contextualización: hacía la mentalidad post-heroica}

Los avances profundos en la pacificación global deben ser explicados. Una aproximación extendida pretende entenderlos como una reacción razonable a las tecnologías de armamento de la revolución industrial: ha sido, por un lado, una adaptación al terror sufrido dos veces por la guerra total entre Estados industrializados con varios millones de víctimas y destrucciones hasta entonces inimaginables (1914-1918, 1939-1945), y por otro lado, una interiorización del desarrollo tecnológico de armas nucleares desde 1945 con la capacidad del overkill múltiple del planeta, plásticamente ilustrada en aproximadamente 2000 pruebas nucleares en la función de gestos de amenaza, de modo que las guerras entre las grandes potencias ya no parecen ganables, pues todos los Estados nucleares participantes se expondrían al riesgo del auto exterminio total por el probable contragolpe nuclear ordenado durante el tiempo de vuelo de los misiles propios (Barash y Webel, 2009, pp. 86 y ss.; Müller, 2008, pp. 158 y ss.).

Además, surgió la nueva experiencia de que en las guerras industriales casi no se logró ganar contra la resistencia civil de sociedades de masa nacionalizadas, que pudieron cansar, por estrategias asimétricas de la guerra pequeña, a las potencias invasoras, así a los Estados Unidos en la Guerra de Vietnam (1965-1975), a Israel en las Intifadas de Palestina (1987-1993, 2000-2005), a la Unión Soviética en la Primera Guerra de Afganistán (1979-1989), de nuevo a los EE. UU. en el caso de la Ocupación del Irak (2003-2011) y al mismo invasor en la Segunda Guerra de 
Afganistán (desde 2001) (Kaldor, 2012, pp. 151-184; Münkler, 2005 b, pp. 47, 93, 144; Münkler, 2010; Pappe, 2006, pp. 228 y ss., 275 y ss.).

En el fondo, se han disuelto por lo menos cinco motivos típicos de guerra: primero, las guerras de expansión no solo son ilegales ahora, sino incluso según la lógica democrática contraproductivas, porque amenazan con hacer del pueblo vencedor, automáticamente, la minoría en las subsiguientes elecciones democráticas. Un ejemplo: si Israel integrara a los territorios palestinos ocupados desde 1967 a su Estado democrático, no se trataría más de un Estado judío con una minoría árabe del 20\%, sino de un Estado binacional paritario, en el cual los árabes ganarían rápidamente, por su crecimiento demográfico superior, la hegemonía democrática (Tilley, 2005, p. 75). La República Democrática Federal de Etiopía se encuentra exactamente en esta situación a causa de la expansión militar del siglo XIX, de modo que los tradicionales pueblos imperiales amárico y tigriña se han convertido en una minoría alrededor del 33\% del total de los etíopes, lo que se maneja por el federalismo étnico (Fessha, 2010, pp. 151 y ss.). Segundo, con la estabilización jurídica de las fronteras y el alto grado de reconocimiento sobre la terminación de la fase de demarcación de las naciones en el resultado de dos siglos de la estatalidad nacional, han desaparecido las guerras por la integración y separación nacional. Desde la última ola de formación de Estados naciones en la década de 1990, es difícil imaginarse nuevos conflictos significativos de este tipo, si se dejan aparte algunas constelaciones puntuales perpetuadas como el conflicto indo-pakistaní de Cachemira (desde 1947). Tercero, se transformaron en menos probables las guerras de la difusión ideológica en vista de la des-ideologización de las relaciones internacionales con el final de la Guerra Fría (1989), aunque tampoco deben subestimarse las tendencias actuales de endurecimiento en las relaciones occidental-islámicas. Cuarto, los mecanismos de decisión de los Estados constitucionales contemporáneos no promueven el honor nacional, sino perciben las guerras industriales como demasiado costosas con enormes riesgos de víctimas que casi no son justificables. Quinto, desapareció casi todo botín de guerra justificable y perdurable -es evidente que no se puede esperar ni territorios, ni tronos, ni tesoros, ni esclavos-, mientras todo cálculo de consecuencias advierte de efectos negativos: un gobierno guerrero obstinado pierde no solo vidas, recursos e infraestructura industrial, sino también reputación, oportunidades de cooperación internacional, el aprovisionamiento con energía fósil, las relaciones del comercio exterior y la entrada de turistas internacionales. 
De igual forma, es instructivo dirigir la vista a la interconexión cosmopolita de las identidades por la globalización de los sistemas de tránsito, de comunicación, de televisión y de consumo que ha provocado una enorme asimilación de las diferencias culturales, así por lo menos, en los tres continentes del círculo cultural europeo-occidental. Desde los años 1950, antiguos rivales como los alemanes y franceses no vivieron de modo aislado, sino se conocieron bien por frecuentes viajes y se entendieron mutuamente por estimar la misma música, los mismos vestidos y los mismos productos. De tal manera, el nacionalismo excluyente de 1789 a 1945, se apaciguó a conceptos democráticos y no chauvinistas como el patriotismo de la constitución (Mejía, 2010, pp. 135-158).

Este es el momento para conectar la pacificación fundamental con las dinámicas inherentes de la gran transformación del sistema agro-civilizatorio al régimen posagrario. Visto a largo plazo, la misma tuvo el efecto de la caída del belicismo agrario y de la figuración heroica de la personalidad, dominante desde diez milenios. A su vez, se impuso en la sociedad industrial madurada la mentalidad posheroica (Münkler, 2005 b, pp. 26, 71, 109, 130, 134) -no solo en los crecientes movimientos pacifistas, sino en toda la sociedad hasta los círculos militares- (Pinker, 2011, pp. 260 y ss., 295 y ss., 671 y ss.; Sheehan, 2008, pp. 172 y ss.). No es el lugar para discutir si el ser humano tiene más una naturaleza violenta o pacifica (Keeley, 1996, pp. 3 y ss.; Fry, 2006, pp. 134 y ss.), pues por lo menos es posible educar el hombre a la paz (Sánchez, 2006, pp. 17 y ss.). De todos modos, si existe en la naturaleza humana una disposición competitiva, la misma fue canalizada desde la violencia física del guerrero hasta la competición estratégica del emprendedor y gerente empresarial. Profundamente, la perspectiva de los ciudadanos masculinos del siglo XIX y de la primera mitad del siglo XX de servir por lo menos una vez en su vida como una comida de tiburones para la batalla, se disolvió en vista del ascenso del nuevo valor civilizatorio de la dignidad humana. En Europa desapareció casi completamente el tema escolar de las grandes batallas, hasta 1945 dominante en la asignatura de historia nacional. Además, comenzó a pertenecer al pasado el pueblo en armas del servicio militar obligatorio, un producto de la anarquía de la soberanía del largo siglo XIX, porque los Estados del núcleo industrial abrieron la posibilidad de objetar por conciencia -por ejemplo, la República Federal Alemana según el artículo 4 número 3 de su Ley fundamental de 1949 (Pieroth y Schlink, 2012, p. 136)-, crearon un servicio social alternativo y legislaron finalmente la derogación de la conscripción: en 1961 Gran Bretaña, en 1972 Australia y Nueva Zelanda, en 1975 
los EE. UU., en 1994 Sudáfrica, en 1995 Argentina y Bélgica, en 1997 los Países Bajos, en 2001 España y Francia, en 2004 Eslovenia, Hungría y Portugal, en 2005 Italia y la República Checa, en 2006 Bosnia-Herzegovina, Eslovaquia, Macedonia y Montenegro, en 2007 Letonia y Romania, en 2008 Bulgaria y Croacia, en 2009 Lituania y Polonia, en 2010 Suecia, en 2011 Alemania y Serbia (Pinker, 2011, pp. 255 y ss.). En el trasfondo, la evaluación de la muerte por la patria como una virtud cívica, fue sustituida por la comprensión de que los grandes ejércitos populares con ideologías nacionalistas habían sido factores decisivos de escalado en los excesos bélicos de las guerras mundiales.

En un proceso complejo de aprendizaje, el poder estatal adoptó cada vez más comportamientos posheroicos y empezó a expresar lamentos y disculpas en las relaciones internacionales en vez de insistir en una especie de honor de guerrero u orgullo nacional. Por lo menos dos desarrollos sistémicos de la transformación industrial motivaron a los Estados a perfeccionar sus capacidades en actuar cooperativamente con sus semejantes: por un lado, desde los años 1950 el extenso metabolismo global de la segunda revolución fósil-energética, requirió un mundo sustancialmente pacificado sin riesgos incalculables para el aprovisionamiento permanente con la fuerza motriz de la civilización industrial, el petróleo; y por otro lado, desde la mitad de los años 1980, la cuestión ambiental de la civilización industrial presionó estructuralmente a la cooperación no egoísta, en particular en los contextos de la crisis de la capa de ozono, la crisis climática y la crisis de sostenibilidad (Hobe y Kimminich, 2004, pp. 472 y ss.; Uribe Vargas y Cárdenas Castañeda, 2010, pp. 32 y ss.).

En suma, se logró canalizar el nacionalismo competidor a meros eventos deportivos entre selecciones nacionales, especialmente en copas de fútbol. No debería verse en todo esto, al igual que el historiador militar israelí Martin van Creveld (1999), una pérdida de la soberanía o incluso la "caída del Estado" (pp. 336 y ss.), pues el Estado se encuentra ahora, por medio de la cooperación global y de la moderación política, más cerca que nunca de la realización eficaz de su fin más tradicional, el de garantizar la paz externa.

\section{La des-imperialización}

La época de la paz mundial garantizada no se despidió de la idea del imperio como tal, pero sí eliminó en 1945 los sueños imperiales de Alemania y Japón y 
solo poco después, dejó implosionar los tres imperios globales del largo siglo XIX -Francia entre 1940 y 1962, Gran Bretaña entre 1941 y 1968 (Ferguson, 2004, 245 y ss.) y Rusia en 1990/1991- que se retiraron al núcleo de su territorio estatal, sin que hubieran sido afectados por causas clásicas de un colapso imperial, aparte de la derrota militar francesa en 1940 (Münkler, 2005 b, p. 119). El abandono del territorio extenso sucedió tan fácil como la adquisición, en vista de los siguientes contextos.

Primero, ni la rápida expansión británica, ni la de su imitador francés, habían construido imperios estables, sino que se trató de fenómenos de corta vida de una constelación extremamente excepcional, es decir, fueron posibilitados por la ventaja inicial de la transformación industrial en la breve ventana de oportunidad entre 1850 y 1910, pero con la difusión progresiva de esta transformación en el planeta, se disolvió su condición de existencia. Segundo, la última Guerra Mundial había demostrado, cuando dos potencias industriales relativamente compactas, Alemania y Japón, habían puesto en apuros los tres Imperios globales, que para la fuerza externa ya no era decisiva la amplia posesión territorial en todo el mundo, sino mucho más la potencia industrial en las fronteras nacionales -y el acceso a recursos energético-petroleros, que tampoco en el lado de los imperios aliados fueron localizados prioritariamente en sus territorios dominados, sino en varios Estados soberanos entre México y Persia-. Tercero, el milagro económico de posguerra que dejó aparecer desde la década de 1950 a los desafiadores y perdedores militares, Alemania y Japón, a pesar de amputaciones territoriales y destrucciones graves, como los verdaderos vencedores (Judt, 2005, pp. 354 y ss.), subrayó otra vez que las superficies externas sometidas no tenían ninguna relevancia positiva para la prosperidad del respectivo Estado. Cuarto, en la época de la globalización de los flujos de materiales, pareció prometedor rediseñar y perfeccionar el sistema mundo industrial entre Estados formalmente soberanos con el fin de optimizar la exportación permanente de mercancías industriales propias y para asegurar la importación perpetua de materias primas según precios cómodos, sin ser más pesado por la necesidad de financiar una administración pública propia en otros continentes. Quinto, la ideología democrática y nacionalista exigió lógicamente una separación, pues en una democracia completa sobre la base del Imperio Británico de 1939, los ingleses hubieran sido una minoría pequeña, como también los rusos hubieran sido en las fronteras pre-1990 en peligro de transformarse de una mayoría débil del $50.7 \%$ en una minoría vencible por mayoría de votos. Sexto, las Naciones 
Unidas ejercieron desde la Resolución 1514 de descolonización del año 1960, por lo menos presión moral (Hobe y Kimminich, 2004, p. 52). Generalmente, el tamaño de la superficie había sido el criterio central de fuerza en las civilizaciones agrarias, cuyo volumen energético había dependido directamente de la extensión territorial por el mecanismo de la transformación de energía solar en biomasa, mientras que las civilizaciones industriales fósil-energéticas se liberaron de la dependencia del tamaño de la superficie.

No obstante, continuaron existiendo Estados militarmente significativos, aunque no fueron siempre los candidatos esperados desde una perspectiva de $1910 \mathrm{o}$ 1930. Habla por sí misma la lista actual de las nueve potencias nucleares del planeta: primero, Rusia con 8500 armas nucleares; segundo, los EE. UU. con 7 700; tercero, Francia con 300; cuarto, China con 240; quinto, Gran Bretaña con 225; sexto y séptimo, Pakistán e India con 100; octavo, Israel con 80; y noveno, Corea del Norte con diez armas nucleares (Federation of American Scientists, 2012). En el armamento con tanques motorizados, los primeros seis Estados del mundo serían Rusia (22 950), EE. UU. (9 573), China (7 500), Corea del Norte (5 410), Unión Europea (5 000) e India (5 000); y en aviones militares hay que indicar, EE. UU. (18 234), Unión Europea (8 300), China (5 176), Rusia (2 749), India (2 462) e Israel (1964) (Global Firepower, 2013). EE. UU., China y Rusia producen aviones furtivos. En términos de alianzas, puede contrastarse la Organización del Tratado del Atántico Norte (OTAN) de 1949 -en su núcleo compuesto por los EE. UU. y la Unión Europea- con la Organización de Cooperación de Shanghái de 2001 -principalmente agregado por China y Rusia-.

En este sentido, nada sería más falso que afirmar un mundo unipolar alrededor de un supuesto "Imperio Americano" (Münkler, 2005 a, pp. 146 y ss.). Sin embargo, no debería desconocerse que, a partir de 1990, los EE. UU. han actuado como la única potencia militar del planeta que mantiene ejércitos significativos en el exterior -especialmente en Alemania, Japón y Corea del Sur-, así como un montón de pequeñas bases militares en varias docenas de Estados; además no están dispuestos a renunciar al antiguo estilo de demostraciones de fuerza e intervenciones imperiales selectivas. Pueden señalarse varias intervenciones militares para tumbar o -raras veces- estabilizar gobiernos, y de vez en cuando, para asegurar flujos de recursos fósil-energéticos, por ejemplo, en 1991 en Irak, en 1992 en Somalia y Bosnia, en 1999 en Serbia, en 2001 en Afganistán, en 2003 en Irak y en 2011 en Libia, pero con resultados que subrayaron, en particular, la creciente impotencia de estas medidas, 
pues se fracasó en Somalia por completo y se provocaron en Afganistán e Irak resistencias amplias, largas y duraderas contra la supuesta neo-cruzada (Münkler, 2010). En un mundo democrático, ya la inmediata elección puede corregir la imposición imperial. No hubo ni dinastías vasallas para implementar, ni relaciones tributarias para asegurar. En cierto sentido, los EE. UU. repiten en la actualidad la experiencia británica de que una superioridad pasajera en la transformación industrial es efímera, pues la progresiva difusión-en este caso la de la segunda revolución fósil-energética con bases del petróleo- agota la ventaja inicial por el creciente ascenso de los demás Estados, con la única diferencia de que el tamaño de los EE. UU. posibilita quedarse por dentro del grupo de las potencias considerables, en conjunto con China, Rusia e India, en vez de limitarse otra vez, al papel de una isla mediocre (Müller, 2008, p. 176; Zakaria, 2011, pp. 100 y ss., 145 y ss., 239 y ss.).

Los cambios en la lógica sistémica pueden subrayarse por la dinámica de la cuestión persa, debido a que los EE. UU. y la Unión Europea temen el ascenso del Estado islámico y petrolero de Irán -en vista de su probable programa nuclear desde 2005-al rango de una potencia militar primaria con una orientación antioccidental, pero la presión por embargos petrolíferos no muestra los efectos deseados, pues Irán ha logrado interconectarse política y económicamente con potencias de una nueva autoestima como China, Japón e India que demandan el petróleo persa según intereses propios, sin orientarse en los deseos y temores de Occidente (Follath y Jung, 2007, pp. 23-24 , 31, 35, 41-42).

\section{Contra-tendencias: el neo-belicismo imperial en forma de guerras preventivas y humanitarias}

Para el régimen de paz mundial de las Naciones Unidas, los EE. UU. se comprueban a veces como una bendición y a veces como una maldición. Son una bendición, cuando ponen su fuerza militar a disposición de las Naciones Unidas, pero son una maldición cuando insisten en una especie de soberanía imperial ilimitada para efectuar políticas en nombre propio. El ejemplo clásico ha sido el rechazo del fallo de la Corte Internacional de Justicia de 1984 contra la intervención ilegal en Nicaragua (Hobe y Kimminich, 2004, pp. 564-565; Meesen, 2005, p. 9; Nussberger, 2010, p. 79).

Sin embargo, a partir de 1999 los EE. UU. empezaron a efectuar, más libremente, políticas neo-soberanas en una interacción estrecha con el ascenso del llamado 
legal realism (Hestermeyer, 2004, pp. 321 y ss.) de la ideología neo-conservadora (Müller, 2008, p. 243). Se atacaron el derecho de la paz mundial con nuevas justificaciones flexibles no previstas de la violencia como la guerra preventiva -retomando una justificación estandarizada de la antigua antropología de guerra tribal (Helbling, 2006) - y la figura de las intervenciones justas en beneficio de valores universales al estilo del supuesto ayudante de los suprimidos y vengador militar frente a gobiernos tiránicos- retomando el núcleo de las justificaciones humanitarias de las políticas coloniales de las potencias europeas en finales del largo siglo XIX (Grewe, 2000, pp. 487 y ss.)-. El fin estratégico de este neo-soberanismo consistió en eludir las instituciones y procedimientos establecidos en el orden mundial de paz por derecho. Sin poder recibir la autorización indispensable del Consejo de Seguridad según el artículo 42 de la Carta de la ONU, la Casa Blanca ignoró -y violó- la prohibición general de la guerra del artículo 2 número 4 de la misma Carta tanto en la Guerra de la OTAN contra Yugoslavia en 1999, justificada como una intervención humanitaria para salvar los kosovares del riesgo de genocidio (que nunca ha sido probable), como en el caso de la invasión de Irak de 2003, justificada como una prevención frente a una supuesta amenaza inmediata con armas de destrucción masiva (que no existieron) y motivada ideológicamente por la difusión del modelo occidental-liberal, geoestratégicamente por el acceso a recursos fósil-energéticos y en general, por implementar un gobierno dócil (Follath y Jung, 2007, p. 17), lo que fue evaluado como ilegal en la opinión predominante de los expertos iusinternacionalistas (Hestermeyer, 2004, pp. 338-339; Hobe y Kimminich, 2004, pp. 339-340; Müller, 2008, p. 168; Murswieck, 2003, pp. 10141020; Nussberger, 2010, pp. 72-73; Paech, 2004, pp. 21-29). De igual forma, la invasión a Afganistán de 2001 y la ocupación continúa solo sería legal, si hubo un caso de la autodefensa legítima, es decir, si el gobierno neo-islámico de los talibán tuvo el control efectivo sobre la red no-estatal de terroristas de Al Qaida que habían atacado con aviones secuestrados a Nueva York, lo que nadie ha podido probar hasta la fecha (Nussberger, 2010, pp. 68-69). Siguió en 2013 la amenaza militar frente a Siria para vengar el supuesto uso de armas químicas frente al pueblo propio, en oposición a la no aprobación explícita por el Consejo de Seguridad de la ONU. Si los EE. UU. pretenden modificar por su práctica particular el artículo 2 número 4 de la Carta de la ONU, hay que responder que hace mucho se acabaron los días en los cuales el Occidente pudo definir de modo unilateral los contenidos del derecho internacional público. 
Paralelamente, se usa la figura de la Guerra contra el terrorismo como una carta blanca para múltiples intervenciones mortales que no entran a la categoría de la guerra abierta, inclusive la ejecución extralegal del líder de Al Qaida Osama bin Laden y de sus familiares en Pakistán (2011) como la Guerra de los drones del servicio secreto CIA en Pakistán (desde 2004) bajo enormes víctimas civiles, incluso niños, y tendencias a un terrorismo de Estado, sin permiso del Estado soberano afectado ni declaración de guerra al mismo (Aniston, 2010, pp. 24 y ss.; Boor, 2011, pp. 97-104; Red. Die Zeit, 2011).

Bajo los signos de una paz hegemónica, los EE. UU. se alejan por lo menos gradualmente de la idea básica de la paz mundial cooperativa, institucionalizada y juridificada. De todos modos, como ya había expuesto con claridad la Paz territorial de Maguncia de 1235, el vengador de la injusticia sufrida o imaginada no es una solución en beneficio de la paz, sino la amenaza principal de la misma (Marquardt, 2012, pp. 229-230).

\section{6. ¿Una Paz de los Estados comerciales?}

En las relaciones globales del siglo XXI ya no es decisivo para el aprecio internacional de un Estado su grado de militarización, sino la potencia industrial medida en el producto interior bruto -con la Unión Europea, los EE. UU. y China en los primeros tres puestos- $\mathrm{y}$ en el volumen de las exportaciones -con los mismos tres actores, pero con China en el segundo puesto y en el caso de la Unión Europea bajo un papel particular de Alemania que por sí solo supera a los EE. UU.-(WTO, 2012). Desde 1945, la dimensión contractual de las relaciones internacionales está dominada por los acuerdos comerciales (Herdegen, 2005, pp. 385-398) que han reemplazado los antiguos pactos de alianzas militares. Embajadas como la alemana apoyan fuertemente los intereses de exportación e importación. La superioridad del comercio internacional sobre la guerra ha sido subrayada por observaciones como la siguiente: en 1942, Alemania fracasó en conquistar los territorios petrolíferos de Rusia en el Cáucaso, pero en el siglo XXI recibe la respectiva energía fósil de modo voluntario por la cooperación comercial (Follath y Jung, 2007, pp. 42 y ss., 150 y ss.). Algo similar puede decirse sobre la relación entre la demanda japonesa y los recursos fósil-energéticos de los tres Estados en la isla de Borneo.

Nada de esto debería ser interpretado como una supuesta victoria pacificadora “de la soberanía del mercado global” (Fleiner y Basta-Fleiner, 2009, pp. 9, 21, 69, 
$73,80)$ frente al Estado, sino como un nuevo modo de interacción cooperativa entre los Estados mismos que han internalizado las posibilidades del metabolismo globalizado de energía y los materiales en la era industrial. Tampoco es una victoria liberal, pues funciona del mismo modo en el caso de la China confuciana-comunista. El trasfondo principal son los profundos cambios de élite en la doble revolución ilustrada e industrial que han reemplazado el liderazgo de los guerreros nobles por el de los comerciantes. Puede realizarse un seguimiento incluso en el lenguaje, teniendo en cuenta la terminología seudo-bélica adoptada por la clase empresarial alrededor de figuras como strategic management, tactics, market offensive, defensive marketing, product strategy, advertising campaign, hostile takeover, etc. En general, la competición comercial requiere la paz, aunque tampoco deben subestimarse las economías de guerra en el contexto de varios conflictos armados en Estados débiles.

\section{Síntesis y conclusiones}

$\mathrm{El}$ articulo ha analizado dos transformaciones del derecho internacional público y de las relaciones internacionales, en primer lugar la de la comunidad de la paz relativa de la Unión Europea de la Edad media a la anarquía de la soberanía entre Estados supuestamente civilizados (1772-1945), y en segundo lugar, la de anarquía de la soberanía a la nueva paz eterna en la tierra en el marco de las Naciones Unidas.

Resumiendo, se disolvieron después de 1945 las lógicas de un sistema internacional bélico en beneficio de la interacción económica de la civilización industrial bajo el ascenso de una fuerte mentalidad posheroica. En el marco institucional de las Naciones Unidas, los Estados no perdieron de su poder estatal -aparte de la soberanía formal, según las antiguas definiciones enfocadas en el ius ad bellumpues ganaron libertades de acción, especialmente porque los recursos, que habían sido reservados para el armamento, pudieron ser desviados en canales políticos más constructivos. Habla muy en contra de la mencionada hipótesis de Martin van Creveld (1999) sobre la supuesta caída del Estado (pp. 336 y ss.), el hecho de que los Estados se garanticen hoy mutuamente su territorio estatal y acepten las fronteras existentes como inviolables. Los grandes avances, pero también la problemática del sistema de paz de Naciones Unidas, los resume el iusinternacionalista Louis Henkin (2013) con exactitud en la fórmula de los cuatro casis: "almost all nations observe almost all principles of international law and almost all of their obligations almost all the time". 
Por supuesto, ya son previsibles los nuevos desafíos del ius contra bellum. Para el siglo XXI, la bibliografía ha hecho plausibles el riesgo de una creciente competitividad interestatal y geoestratégica por los últimos recursos fósil-energéticos ante el escenario de escasez del Peak Oil (Follath y Jung, 2007), y la posibilidad de guerras ambientales y climáticas en el marco de la creciente devastación ambiental de la civilización industrial (Welzer, 2010). Por lo tanto, va a ser clave que el régimen supranacional los manejará con la sabiduría y moderación de una verdadera cultura de la paz cooperativa y juridificada.

\section{Referencias}

(1648) Paz de Westfalia, Instrumentum Pacis Monasteriensis (I.P.M.) y Instrumentum Pacis Osnabrugensis (I.P.O.), traducción en español de 1750, por Abreu y Bertodano, J. A. de (Ed.). Coleccion De los tratados de Paz, Alianza, Neutralidad, Garantia [...], Reynado del Sr. Rey D. Phelipe IV, Parte V, Madrid: A. Marin, J. de Zuñiga, y la Viuda de Peralta, 1750, pp. 476-480, digitalizado por Vereinigung zur Erforschung der neueren Geschichte (Ed.). Acta Pacis Westphalicae, Supplementa electronica, 1, http://www.paxwestphalica.de/ipmipo/pdf/m_1750sp-abreu.pdf(03.09.2013).

(1758) Vattel, E. de. Le droit des gens ou principes de la loi naturelle. Londres: 1758. Traducción en español: El Derecho de gentes, ó, Principios de la ley natural. Madrid: Ed. Ibarra, 1822. (1772) Tratados de San Petersburgo de 1772, de 1793 y de 1795. ed. por Grewe, W. G. Fontes Historiae Iuris Gentium: Sources Relating to the History of the Law of Nations, tomo 2, 1493-1815. Berlín y Nueva York: De Gruyter, 1988, pp. 613-645.

(1777) Moser, J. J. Grundsätze des jetzt üblichen Europäischen Völkerrechts in Friedenszeiten ( $2^{\mathrm{a}}$ ed.). Núremberg, 1777.

(1793) La déclaration du droit des gens de l'abbé Grégoire, Étude sur le droit international public intermédiaire, 1793/1795, Imprimerie P. Barbey, 1912.

(1806) Declaración de independencia de los Estados de la Confederación de Rin y Abdicación del Sacro Emperador Romano Francisco II. ed. por Grewe, W. G. Fontes Historiae Iuris Gentium: Sources Relating to the History of the Law of Nations, tomo 2, 1493-1815. Berlin y Nueva York: De Gruyter, 1988, pp. 692-693, 694-696.

(1815) Tratado general, o sea Acta del Congreso de Viena, que firmaron el 9 de julio de 1815 los plenipotenciarios de Austria, Francia, Inglaterra, Portugal, Prusia, Rusia y Suecia. en Cantillo, A. del (Ed.). Tratados, convenios y declaraciones de paz y de comercio. Madrid: Imp. de Alegría y Charlain, 1843. 
(1856) Paz de París entre el Imperio Otomano, Francia, Gran Bretaña y el Imperio Ruso. ed. por Grewe, W. G. Fontes Historiae Iuris Gentium: Sources Relating to the History of the Law of Nations, tomo 3-1, 1815-1945. Berlín y Nueva York: De Gruyter, 1992, p. 22. (1864) Convention for the Amelioration of the Condition of the Wounded in Armies in the Field, Geneva, http://www.icrc.org/ihl.nsf/WebSign?ReadForm Eंid=120E'ss=P(07.09.2013).

(1872) Bluntschli, J. C. Das moderne Völkerrecht der civilisirten Staten. Nördlingen: Beck, 1872.

(1890) Resolución de la Primera Conferencia Panamericana, ed. por Grewe, W. G. Fontes Historiae Iuris Gentium: Sources Relating to the History of the Law of Nations, tomo 3-1, 1815-1945. Berlín y Nueva York: De Gruyter, 1992, pp. 243 y s.

(1919) Tratados de Versalles, de St. Germain, de Neuilly, de Trianon y de Sevres. ed. por Grewe,

W. G. (Ed.). Fontes Historiae Iuris Gentium: Sources Relating to the History of the Law of Nations, tomo 3-2, 1815-1945. Berlín y Nueva York: De Gruyter, 1992, pp. 683-718. (1928) Pacto Briand-Kellogg, ed. por Grewe, W. G. Fontes Historiae Iuris Gentium: Sources Relating to the History of the Law of Nations, tomo 3-2, 1815-1945. Berlin y Nueva York: De Gruyter, 1992, pp. 959 y ss.

(1945) Carta de las Naciones Unidas, firmada en San Francisco el 26 de junio 1945, http:// www.un.org/spanish/aboutun/charter/index.htm (07.09.2013).

(1948) Convención para la Prevención y la Sanción del Delito de Genocidio, ed. por Oficina del Alto Comisionado de las Naciones Unidas para los Derechos Humanos, http://www2. obchr.org/spanish/law/genocidio.htm (07.09.2013).

(1948) Declaración Universal de los Derechos Humanos, ed. por Oficina del Alto Comisionado de las Naciones Unidas para los Derechos Humanos, http://www.ohchr.org/en/udhr/ pages/introduction.aspx (07.09.2013).

(1990) Tratado dos más cuatro sobre el acuerdo final con respecto a Alemania, ed. por U.S.

Diplomatic Mission to Germany, http://usa.usembassy.deletexts/2plusfour8994e.htm (07.09.2013).

(2009) Warrant of Arrest for Omar Hassan Ahmad Al Bashir, de 4 de marzo de 2009, Corte Penal Internacional, bttp://www.icc-cpi.int/iccdocs/doc/doc639078.pdf(07.09.2013).

\section{Bibliografía secundaria}

Alston, P. (2010). Report of the Special Rapporteur on extrajudicial, summary or arbitrary executions: Study on targeted killings. Nueva York: UN General Assembly, Human Rights Council.

Azoulay, A. y Ophir, A. (2013). The One-State Condition: Occupation and Democracy in Israel/ Palestine, Stanford: University Press. 
Barash, D. P. y Webel, C. P. (2009). Peace and Conflict Studies (2 ed.). Thousand Oaks: Sage Publications.

Bogdandy, A. v. y Hinghofer-Szalkay, S. (2013). Das etwas unheimliche Ius Publicum Europaeum. revista Zeitschrift für ausländisches öffentliches Recht und Völkerrecht. vol. 73, núm 2. Múnich: Verlag C.H. Beck, pp. 209-248.

Boor, F. (20I I). Der Drohnenkrieg in Afghanistan und Pakistan. revista Humanitäres Völkerrecht. núm. 24. Berlín \& Bochum: Deutsches Rotes Kreuz y Ruhr Universität, pp. $97-104$.

Bothe, M. (2010). Friedenssicherung und Kriegsrecht. en Vitzthum, W. (Ed.). Völkerrecht (5 ed.). Berlín y Nueva York: De Gruyter.

Boyle, F. (2010). The Great Irish Famine was Genocide. en Global Research (Ed.). Crimes against humanity, http://www.globalresearch.ca/the-great-irish-famine-was-genocide/ (07.09.2013).

Calic, M. J. (2010). Geschichte Jugoslawiens im 20. Jahrhundert. Bonn: BPB.

Comins Mingol, I. (2009). Filosofía del cuidar: Una propuesta coeducativa para la paz. Barcelona: Icaria.

Creveld, M. v. (1999). The Rise and Decline of the State. Cambridge: University Press.

D'Anieri, P. (2012). International Politics: Power and Purpose in Global Affairs (2a ed.). Boston: Wadsworth.

Davies, N. (2005). God's Playground: A History of Poland. tomo 1. Oxford: University Press. Doering-M., A. (2001). Die deutsche Frage und das europäische Staatensystem 1815-1871. Múnich: Oldenbourg Wissenschaftsverlag.

Dörr, O. (1995). Die Inkorporation als Tatbestand der Staatensukzession. Berlín: Duncker \& Humblot.

Duchhardt, H. (1999). Westphalian System: Zur Problematik einer Denkfigur. revista Historische Zeitschrift.vol. 269. Múnich: Oldenbourg Wissenschaftsverlag, pp. 305-315. Duchhardt, Heinz (2004). Peace treaties from Westphalia to the Revolutionary Era. en Lesaffer, R. (Ed.). Peace Treaties and International Law in European History. Cambridge: University Press, pp. 45-58.

Dyrchs, S. (2008). Das hybride Khmer Rouge-Tribunal. Fráncfort del Meno: Peter Lang Europäischer Wissenschaftsverlag.

Eglauer, M. (2005). Die Wahrnehmung des Fremden: Die Rolle des Westens beim Modernisierungsprozess in China. Stuttgart: Breuninger.

Federation of American Scientists (201 2). Status of World Nuclear Forces End 2012, bttp:// www.fas.org/programs/ssp/nukes/nuclearweapons/nukestatus. html (07.09.2013).

Ferguson, N. (2003). Empire: How Britain made the modern world. Nueva York: Basic Books. 
Ferguson, N. (2004). Empire: The rise and demise of the British World Order and the lessons for global power. Nueva York: Basic Books.

Fessha, Y. T. (2010). Ethnic Diversity and Federalism: Constitution Making in South Africa and Ethiopia. Farnham: Ashgate Publishing.

Fisas, V. (2006). Cultura de paz y gestión de conflictos (5a ed.). Barcelona: Icaria.

Fleiner T. y Basta-Fleiner, L. R. (2009). Constitutional democracy in a multicultural and globalised world. Berlín: Springer. Ttítulo original en alemán: Allgemeine Staatslehre: Über die konstitutionelle Demokratie in einer multikulturellen globalisierten Welt (3 $3^{\mathrm{a}}$ ed.). Berlín: Springer, 2004.

Follath, E y Jung, A. (2007). Der neue kalte Krieg um die Rohstoffe. Bonn: BPB.

Fry, D. P. (2006). The human potential for peace: An Anthropological Challenge to Assumptions about War and Violence, Oxford: University Press.

Gareis, S. y Varwick, J. (2005). The United Nations: An introduction, Houndmills: Palgrave Macmillan. Título original en alemán: Die Vereinten Nationen: Aufgaben, Instrumente und Reformen (2 ed.). Opladen: Verlag Barbara Budrich, 2002.

Gerlach, C. (2010). Extremely Violent Societies: Mass Violence in the 20 th-Century World. Nueva York: Cambridge University Press.

Global Firepower (2013). Total aircraft by country and Total tank strength by country, http://www.globalfirepower.com/aircraft-total.asp \& http://www.globalfirepower.com/ armor-tanks-total.asp (07.09.2013).

Grewe, W. G. (2000). The epochs of international law. Berlín y Nueva York: De Gruyter. Título original en alemán: Epochen der Völkerrechtsgeschichte (2a ed.). Baden Baden: Nomos Verlag, 1988.

Hattenhauer, H. (1999). Europäische Rechtsgeschichte (3ª ed.). Heidelberg: C.F. Müller Verlag.

Helbling, J. (2006). Tribale Kriege: Konflikte in Gesellschaften obne Zentralgewalt. Fráncfort del Meno: Campus Verlag.

Henkin, L. (2013). Preeminent Scholar in Constitutional and International Law, http://www. law.columbia.edu/louis-henkin/55703 (07.09.2013).

Herdegen, Matthias (2005). Derecho internacional público. México: Universidad Nacional Autónoma de México y Konrad Adenauer Sitftung. Título original en alemán: Völkerrecht (4 ed.). Múnich: Verlag C.H. Beck, 2005.

Hestermeyer, H. P. (2004). Die völkerrechtliche Beurteilung des Irakkrieges im Lichte transatlantischer Rechtskulturunterschiede. revista Zeitschrift für ausländisches öffentliches Recht und Völkerrecht. vol. 64. Múnich: Verlag C.H. Beck, pp. 315-341.

Hillgruber, C. (1998). Die Aufnahme neuer Staaten in die Völkerrechtsgemeinschaft. Fráncfort del Meno: Peter Lang Europäischer Wissenschaftsverlag. 
Hobe, S. y Kimminich, O. (2004). Einfübrung in das Völkerrecht ( $8^{\mathrm{a}}$ ed.). Tübingen: UTB Verlag.

Hobsbawm, E. (2001). La era del Imperio 1875-1914. Barcelona: Ed. Crítica. Título original en inglés: The Age of Empire 1875-1914. Londres: Weidenfeld \& Nicholson, 1987.

Hobsbawm, E. (2005). La era de la revolución 1789-1848 (3a ed.). Barcelona: Ed. Critica. Título original en inglés: The age of revolution, Europe 1789-1848. Londres: Weidenfeld \& Nicholson, 1962.

Judt, T. (2005). Postwar: A History of Europe since 1945. Nueva York: Penguin, 2005.

Kaldor, M. (2012). New and old Wars: Organised Violence in a Global Era (3 $3^{\mathrm{a}}$ ed.). Cambridge: Polity Press.

Keeley, L. H. (1996). War before civilization: The myth of the peaceful savage. Oxford: University Press.

Kimminich, O. (1990). Einfübrung in das Völkerrecht (4a ed.). Múnich: K.G. Saur Verlag.

Kinder, H. y Hilgemann, W. y Hergt, M. (2012). Atlas histórico mundial: De los orígenes a nuestros días (reimpresión). Tomo 2. Madrid: Eds. Akal. Título original en alemán: DTV-Atlas Weltgeschichte: Von den Anfängen bis zur Gegenwart (2a ed.). Múnich: Deutscher Taschenbuch Verlag, 2008.

Kotulla, M. (2008). Deutsche Verfassungsgeschichte: Vom Alten Reich bis Weimar (1495-1933). Berlín: Springer Verlag.

Kokott, J. (2000). Naturrecht und Positivismus im Völkerrecht. en Meier-Schatz, C. et al. (Eds.). Recht und Internationalisierung. Zurich: Schulthess Verlag, pp. 3-22.

Laughland, J. (2008). History of Political Trials: From Charles I to Saddam Hussein. Oxford: Peter Lang.

Lesaffer, R. (2004). Peace Treaties from Lodi to Westphalia. en Íd. (Ed.). Peace Treaties and International Law in European History. Cambridge: University Press, pp. 9-44.

Lukowski, J. (1999). The partitions of Poland 1772, 1793, 1795, Londres y Nueva York: Longman.

Mann, G. (2008). Deutsche Geschichte des 19. und 20. Jahrhunderts (11 ${ }^{\mathrm{a}}$ ed.). Fráncfort del Meno: Fischer Tachenbuch Verlag.

Mann, M. (2006). The Dark Side of Democracy: Explaining Ethnic Cleansing. Cambridge: University Press.

Marquardt, Bernd (2005). Die Europäische Union des vorindustriellen Zeitalters: Vom Universalreich zur Respublica Christiana des Jus Publicum Europaeum (800 - 1800). Zurich: Schulthess Verlag.

Marquardt, Bernd (2007). El mito del sistema de Westfalia: Una reevaluación de la cesura de 1648 en la historia del derecho internacional público. revista Pensamiento Jurídico, núm. 20. Bogotá: Universidad Nacional de Colombia, pp. 103-134. 
Marquardt, Bernd (2009 a). ¿Paz por estatalización, Paz por Cortes de Justicia, Paz por tratado, Paz por soberanía, Paz por derecho penal? Acercamiento al tema de la Paz desde la Perspectiva de la Historia del Derecho. revista Pensamiento Jurídico, núm. 26. Bogotá: Universidad Nacional de Colombia, pp. 17-60.

Marquardt, Bernd (2009 b). Historia Universal del Estado, tomo 3, El Estado de la doblerevolución ilustrada e industrial. Bogotá: Universidad Nacional de Colombia.

Marquardt, Bernd (2012). Historia Mundial del Estado, tomo 1, Sociedades preestatales y Reinos dinásticos (2a ed.). Bogotá: Temis.

Marquardt, Bernd (2013). Historia Mundial del Estado, tomo 2, El Estado judicial de la paz interna en Europa (siglos XVI-XVIII) (2a ed.). Bogotá: Temis.

Meessen, K. M. (2005, febrero). Völkerrecht in der Pax Americana. Neue Zürcher Zeitung, núm. 42 , p. 9.

Mejía Quintana, O. (2010). Patriotismo de la constitución y opinión pública. revista Diálogos de saberes, Investigaciones y ciencias sociales, núm. 32. Bogotá: Universidad Libre, pp. 135-158.

Monroy Cabra, M. G. (2002). Derecho internacional público (5ª ed.). Bogotá, Temis.

Müller, H. (2008). Wie kann eine neue Weltordnung aussehen? Wege in eine nachhaltige Politik. Bonn: BPB.

Müller, R. (2009). Militärgeschichte, Colonia, Viena y Weimar: Böhlau Verlag.

Münkler, H. (2005 a). Empires: The Logic of World Domination from Ancient Rome to the United States. Cambridge: Polity Press. Título original en alemán: Imperien: Die Logik der Weltherrschaft, Vom Alten Rom bis zu den Vereinigten Staaten. Berlín: Rowohlt, 2005.

Münkler, H. (2005 b). The New Wars. Cambridge: Polity Press. Título original en alemán: Die Neuen Kriege. Reinbek bei Hamburg: Rowohlt, 2002.

Münkler, H. (2010, mayo). Das Scheitern des Westens. Süddeutsche Zeiung, http://www. sueddeutsche.de/politik/nato-einsatz-in-afghanistan-das-scheitern-des-westens-1.390507 (07.09.2013).

Murswieck, D. (2003). Die amerikanische Präventivstrategie und das Völkerrecht. revista Neue Juristische Wochenschrift. Múnich: Verlag C.H. Beck, pp. 1014-1020.

Naimark, N. M. (2001). Fires of Hatred: Ethnic Cleansing in Twentieth-Century Europe. Harvard: University Press.

Neugebauer, K. (2007). Grundkurs deutsche Militärgeschichte, tomo 2, Das Zeitalter der Weltkriege. Múnich: Oldenbourg Wissenschaftsverlag.

Nipperdey, T. (1985). Deutsche Geschichte 1800-1866: Bürgerwelt und starker Staat. Múnich: Verlag C.H. Beck.

Nussberger, A. (2010). Das Völkerrecht: Geschichte, Institutionen, Perspektiven. Bonn: BPB. 
Osiander, A. Sovereignty, International Relations, and the Westphalian Myth. revista International Organization. Vol. 55, núm. 2. Cambridge: University Press, pp. 251-287. Paech, N. (2004). Epochenwechsel im Völkerrecht? Über die Auswirkungen der jüngsten Kriege auf das UNO-Friedenssystem. revista Aus Politik und Zeitgeschichte, núm. B 43. Bonn: BPB, pp. 21-29.

Pappe, I. (2006). A history of modern Palestine (2a ed.). Cambridge: University Press.

Pappe, I. (2011). The Ethnic Cleansing of Palestine (4a ed.). Oxford: Oneworld.

Pieroth, B. y Schlink, B. (2012). Grundrechte, Staatsrecht II (28 ed.). Heidelberg: C.F. Müller Verlag.

Pinker, S. (2011). The Better Angels of our Nature: Why Violence has declined. Nueva York: Viking Penguin.

Polanyi, K. (2003). La gran transformación: Los orígenes políticos y económicos de nuestro tiempo ( $2^{a}$ ed.). México: Fondo de Cultura Económica. Título original en inglés: The great transformation: The political and economic origins of our time. Boston: Beacon Press, 2001.

Redacción Die Zeit (2011, mayo). Völkerrecht: Altkanzler Schmidt verurteilt Tötung bin Ladens. Die Zeit, http://www.zeit.de/politik/deutschland/2011-05/schmidt-bin-laden (07.09.2013).

Richards, E. (1985). A History of the Highland Clearances. Beckenhem: Croom Helm.

Rojas, D.M. (2005). La historia y las relaciones internacionales: De la historia internacional a la historia global. revista Historia Crítica, núm. 27. Bogotá: Universidad de los Andes, pp. 153-168.

Rummel, R. J. (I 997). Death by Government: Genocide and Mass Murder since 1900. New Brunswick: Transaction Publishers.

Sánchez Cardona, M. (2006). Educación para la paz: Teoría y práctica. Bogotá: Riegel.

Sheehan, J. J. (2008). Where Have All the Soldiers Gone? The Transformation of Modern Europe. Nueva York: Houghton Mifflin.

Sieferle, R. P. (2009). El camino especial de Europa. en Íd. y Marquardt, B. La Revolución Industrial en Europa y América Latina: Interpretaciones ecobistóricas desde la perspectiva de la Teoría de los Sistemas de Energía y del Metabolismo Social. Bogotá: Universidad Nacional de Colombia, pp. 1-92.

Steiger, H. (2004). Peace treaties from Paris to Versailles. en Lesaffer, R. (Ed.). Peace Treaties and International Law in European History. Cambridge: University Press, pp. 59-99.

Stolleis, M. (2009). La historia del derecho como obra de arte. Granada: Comares. Título original en alemán: Rechtsgeschichte als Kunstprodukt, Zur Entbehrlichkeit von Begriff und Tatsache, Baden Baden: Nomos Verlagsgesellschaft, 1997.

Tilley, V. (2005). The One-State Solution: A Breakthrough for Peace in the Israeli-Palestinian deadlock. Ann Arbor: University of Michigan Press. 
Tomuschat, C. (2004). The 1871 Peace Treaty between France and Germany and the 1919 Peace Treaty of Versailles. en Lesaffer, R. (Ed.). Peace Treaties and International Law in European History. Cambridge: University Press, pp. 382-396.

Tomuschat, C. (2008). Humanitäre Intervention: Ein trojanisches Pferd? en Münkler, H. y Malowitz, K. (Eds.). Humanitäre Intervention: Ein Instrument außenpolitischer Konfliktbearbeitung. Wiesbaden: VS Verlag für Sozialwissenschaften, pp. 65-88.

Truyol y Serra, A. (1998). Historia del derecho internacional público. Madrid: Tecnos. Título original en francés: Histoire du droit internacional public. París: Economica, 1995.

Uribe Vargas, D. \& Cárdenas Castañeda, F. A. (2010). Derecho Internacional Ambiental. Bogotá: Universidad Tadeo Lozano.

Vergara Molana, A. (2002). Derecho internacional público (3a ed.). Bogotá: G \& B Graphic. Vickers, A. (2005). A History of Modern Indonesia. Cambridge: University Press.

Wehler, H. U. (1995). Deutsche Gesellschaftsgeschichte, tomo 3, Von der Deutschen Doppelrevolution bis zum Beginn des Ersten Weltkriegs, 1849-1914. Múnich: Verlag C.H. Beck.

Welzer, H (2010). Guerras climáticas: Por qué mataremos (y nos matarán) en el siglo XXI. Buenos Aires: Katz. Título original en alemán: Klimakriege: Wofür im 21. Jabrbundert getötet wird. Fráncfort del Meno: Fischer Verlag, 2008.

Willoweit, D. (2009). Deutsche Verfassungsgeschichte: Vom Frankenreich bis zur Wiedervereinigung (6a ed.). Múnich: Verlag C.H. Beck.

WTO (2012). World Trade 2011: Prospects for 2012, Trade growth to slow in 2012 after strong deceleration in 2011, http://www.wto.org/english/news_elpres12_e/pr658_e.htm (07.09.2013).

Zacher, M. W. (2001). The Territorial Integrity Norm: International Boundaries and the Use of Force. revista International Organization. vol. 55, núm. 2. Cambridge: University Press, pp. 215-250.

Zakaria, F. (2011). The Post-American World (2a ed.). Nueva York: Norton.

Ziegler, K. H. (2004). The peace treaties of the Ottoman Empire with European Christian Powers. en Lesaffer, R. (Ed.). Peace Treaties and International Law in European History. Cambridge: University Press, pp. 338-364.

Ziegler, K. H. (2007). Völkerrechtsgeschichte (2a ed.). Múnich: Verlag C.H. Beck. Yaron, G. (2008). Jerusalem. Bonn: BPB. 